\title{
Pediatric Lymphoid and Histiocytic Lesions in the Head and Neck
}

\author{
A. Auerbach ${ }^{1}$ [ $\cdot$ J. J. Schmieg ${ }^{1}$ ' N. S. Aguilera ${ }^{2}$
}

Received: 16 September 2020 / Accepted: 19 November 2020 / Published online: 15 March 2021

(c) This is a U.S. Government work and not under copyright protection in the US; foreign copyright protection may apply 2021

\begin{abstract}
Lymphoid and histiocytic lesions of the head and neck in pediatric patients is a fascinating topic as most of these lesions are benign, but that the neoplastic cases are essential to diagnose accurately for appropriate treatment. It is thought that $90 \%$ of children will have palpable lymph nodes between the ages of 4 to 8 ; most, but not all, are non-malignant and some resolve spontaneously without treatment. This paper will look at many of the benign and malignant lesions of both lymphocytic and histiocytic origin that present in the head and neck of children focusing on their diagnostic criteria. There is a very pertinent discussion of nonmalignant lymphoid proliferations, as infections and other reactive conditions dominate the pathology of pediatric lymphohistiocytic head and neck lesions. Discussion of those lymphomas which arise more frequently in the head and neck focuses on those seen in children and young adults such as classic Hodgkin lymphoma and Burkitt lymphoma, as well as new more controversial entities such as pediatric-type follicular lymphoma. Histiocytic lesions, both benign and malignant, are described and may be challenging to diagnose.
\end{abstract}

Keywords Hematopathology $\cdot$ Lymphoma $\cdot$ Follicular hyperplasia $\cdot$ Paracortical hyperplasia $\cdot$ Pediatric-type follicular lymphoma Classic Hodgkin lymphoma $\cdot$ Langerhan cell sarcoma

\section{Non-neoplastic Reactive Lymphoid Proliferations}

Non-neoplastic reactive proliferations in head and neck lymphoid tissue including lymph nodes, tonsils, and adenoids are common occurrences in the pediatric population that occasionally result in biopsy specimens requiring histopathologic analysis [1, 2]. In many reactive lymphoid proliferations, the histopathologic features are non-specific and not indicative of any particular underlying etiology. In some cases, however, the constellation of microscopic findings strongly suggests specific etiologies or diagnostic entities. Depending on the morphologic features of a particular specimen and the clinical findings of the patient, correlation with ancillary techniques including immunohistochemistry, flow cytometry, cytogenetics, and/or molecular testing might be required to properly characterize a reactive lymphoid proliferation and distinguish it from neoplastic mimics. As a

A. Auerbach

aaron.auerbach.civ@mail.mil

1 The Joint Pathology Center, Silver Spring, MD, USA

2 University of Virginia Health System, Charlottesville, VA, USA general rule, reactive proliferations will show normal immunophenotypic features and no evidence of a clonal genetic finding. In addition to these ancillary studies, clinical history, radiographic findings, and other laboratory data from the patient might provide critical information needed for a correct diagnosis.

There are a number of different morphologic patterns that can be seen in reactive proliferations of head and neck lymphoid tissue including follicular hyperplasia, paracortical/ interfollicular hyperplasia, granulomatous processes, nongranulomatous necrotizing processes, sinus proliferations, and mixed pattern hyperplasia [3]. Cognizance of these patterns can help in generating a comprehensive differential diagnosis, which is important in guiding further ancillary testing. While the number of potential non-neoplastic reactive etiologies that can generate these different patterns is vast, in general they will be due to either infectious agents or autoimmune/autoinflammatory disorders. What follows is a discussion of selected non-neoplastic reactive disease entities that occur in children, which illustrate some of the common morphologic patterns seen in reactive lymphoid tissues of the head and neck.

Castleman disease $(C D)$ is a non-neoplastic lymphoproliferative disorder characterized histologically by a follicular 
hyperplasia pattern. It is an uncommon disorder; however, it can occur at any age including in children. Moreover, approximately $70 \%$ of pediatric CD cases occur in head and neck tissues including cervical lymph nodes and parotid gland so recognition of this entity is important for head and neck pathologists dealing with pediatric specimens [4]. Clinically, $\mathrm{CD}$ is divided into localized (unicentric CD [UCD]) and systemic (multicentric CD [MCD]) forms. UCD typically presents as an isolated mass involving a single lymph node or multiple lymph nodes in the same region, and aside from mass effect is usually asymptomatic. MCD involves lymph nodes in 2 or more regions and commonly presents with systemic symptoms and laboratory abnormalities believed to be mediated by hypercytokinemia. These include fever, weight loss, fatigue, anemia, hypergammaglobulinemia, elevated ESR, elevated CRP, and elevated IL-6. MCD is further divided into HHV8-positive MCD, which is typically associated with HIV infection, and HHV8-negative idiopathic MCD, which usually occurs in HIV-negative patients [5]. The great majority ( 75-95\%) of pediatric CD cases are UCD $[4,6]$.

While clinical, radiographic, and laboratory data are needed for the proper classification of $\mathrm{CD}$, the diagnosis cannot be made without histopathologic evaluation, usually of a suspicious lymph node [4]. Histologically, CD is divided into 3 subtypes: hyaline vascular (HV), plasma cell (PC), and mixed types. In all 3, follicular hyperplasia is a constant feature. In UCD, the HV pattern is seen in the great majority of cases, ranging from $74.4 \%$ to $92.5 \%$ in large series of pediatric and adult patients, and is therefore most relevant to pediatric patients $[4,5]$. The distribution of histologic types in MCD is more variable, with the 3 different patterns seen in approximately equal numbers [7]. The $\mathrm{HV}$ pattern of $\mathrm{CD}$ is characterized by increased numbers of germinal centers (GCs) exhibiting regressed or atretic features distributed throughout the entirety of the lymph node (Fig. 1a). These GCs classically demonstrate concentric "onion skinning" of mantle zone lymphocytes (Fig. 1a-c), deposition of hyalinized proteinaceous material, and prominent follicular dendritic cells. In some cases, multiple GCs may be encompassed by a single mantle zone (Fig. 1a and b). The interfollicular area is characterized by a population of small lymphocytes, as well as increased vascularity consisting mostly of hyalinized capillaries including some that extend into and penetrate regressed GCs forming so-called "lollipop GCs" (Fig. 1b and c). In the PC type of CD, the interfollicular area demonstrates a sheet-like proliferation of mature plasma cells in a background of follicular hyperplasia consisting mostly of conventional non-regressed GCs. In the mixed type of $\mathrm{CD}$, there is follicular hyperplasia with a mixture of regressed and non-regressed GCs and an interfollicular region containing both hypervascular and plasma cell-rich areas. An additional histologic feature of CD that can be seen in HHV8-positive cases are variable numbers of plasmablasts in mantle zones, which stain positive for HHV8 by immunohistochemistry. Although the differential
Fig. 1 Castleman Disease; lymph node. a Scanning-power H\&E view showing follicular hyperplasia with many regressed germinal centers including several sharing a single mantle zone. b Lowpower $\mathrm{H} \& \mathrm{E}$ view showing a "double germinal center" at the bottom of the image and the interfollicular area at the top characterized by a population of small lymphocytes and increased vascularity consisting mostly of hyalinized capillaries. c Medium-power H\&E view showing a regressed "lollipop" germinal center with its characteristic penetrating sclerotic capillary, as well as prominent "onion skinning" of the mantle zone
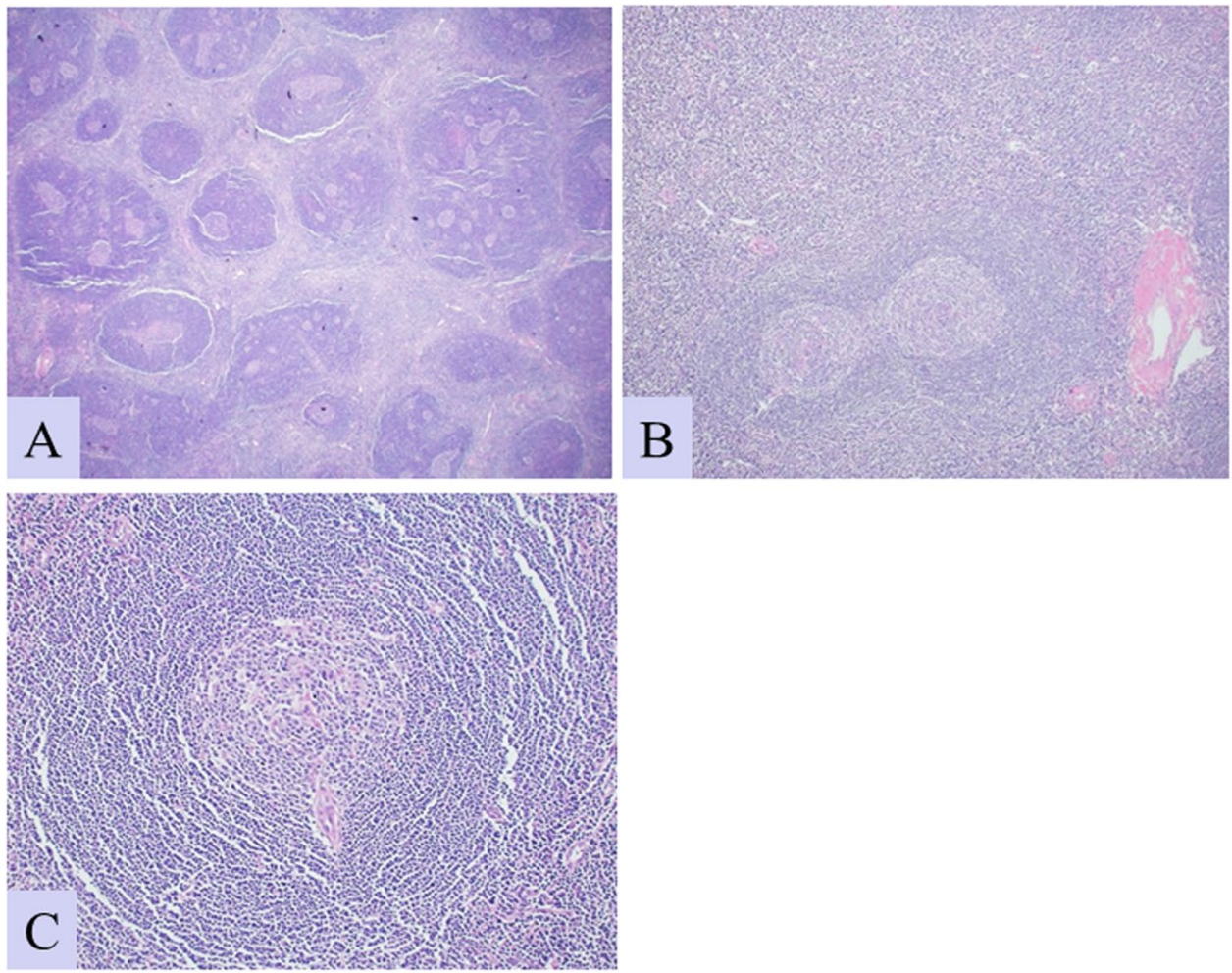
diagnosis for $\mathrm{CD}$ can include non-Hodgkin lymphomas such as follicular lymphoma and marginal zone lymphoma with plasmacytic differentiation, the histologic features are usually characteristic enough to distinguish these entities.

Infectious mononucleosis (IM) caused by acute EBV infection is a common occurrence in the pediatric population, most often effecting teenagers. IM classically presents with fever, sore throat, cervical lymphadenopathy, splenomegaly, and peripheral blood lymphocytosis consisting of large reactive lymphocytes (Downey cells). The vast majority of IM cases are diagnosed serologically (e.g., Monospot test or EBV-specific serologies) and do not require a biopsy [8]. In atypical presentations, however, a biopsy specimen may be collected to rule out lymphoma or some other pathologic process. In these scenarios, the specimen is often an enlarged cervical lymph node or a tonsil. The histopathologic features of IM common in both lymph node and tonsil specimens can mimic lymphoma so awareness of these features is important in preventing an incorrect diagnosis [9].

The lymphadenitis seen in IM is a prototypical example of florid paracortical hyperplasia (Fig. 2a). The lymph node architecture is preserved but distorted by a proliferation of reactive paracortical immunoblasts that in areas may form confluent sheets with associated focal necrosis (Fig. 2b). These reactive immunoblasts consist mostly of activated CD8 + cytotoxic T-cells that frequently show co-expression of CD30 and occasionally express the EBV markers EBVLMP1 and EBER (Fig. 2c and d). Scattered large atypical multinucleated cells reminiscent of Reed-Sternberg (RS) cells are also usually present (Fig. 2b), which are typically positive for pan B-cell markers like CD20, CD79a, and PAX5, as well as CD30, CD45, EBV-LMP1, and EBER (Fig. 2d). The sinuses are patent, and in most areas distended by intrasinusoidal reactive $\mathrm{CD} 8+$ immunoblasts, which correspond to the Downey cells seen in peripheral blood. Scattered variably sized reactive germinal centers are commonly seen, but these are usually not a conspicuous feature. In IM tonsil specimens, the features are similar to those seen in lymph nodes, with expansion of the interfollicular area by increased numbers of reactive immunoblastic cells accompanied by variably sized reactive germinal centers. Ulceration and necrosis can sometimes be seen with an adjacent proliferation of large B-cells including some RS-like forms; however, such features are usually focal with the overall tonsillar architecture intact [9].

The differential diagnosis for the histologic features seen in IM include large cell non-Hodgkin lymphomas, classic Hodgkin lymphoma, other viral lymphadenitides such as CMV and HSV 1 and 2, and autoimmune lymphoproliferative syndrome (ALPS). In patients with iatrogenic immunosuppression such as occurs in the post-transplant setting, other differential diagnostic considerations would include the early non-destructive IM-like posttransplant lymphoproliferative disorder (PTLD) and the newly recognized entity EBV-positive mucocutaneous ulcer, both of which commonly occur in mucosal sites of the head and neck including
Fig. 2 Infectious Mononucleosis; lymph node. a Low-power H\&E view showing prominent paracortical hyperplasia surrounding two small germinal centers. b Medium-power H\&E view of hyperplastic paracortex showing numerous transformed immunoblasts, occasional large Reed-Sternberg (RS)-like cells, and a small focus of necrosis. c Immunohistochemical stain for CD8 showing abundant CD8 + T-immunoblasts in paracortex and distending sinuses. $\mathbf{d}$ In situ hybridization (ISH) for EBER showing EBV positivity in both RS-like cells and occasional immunoblasts
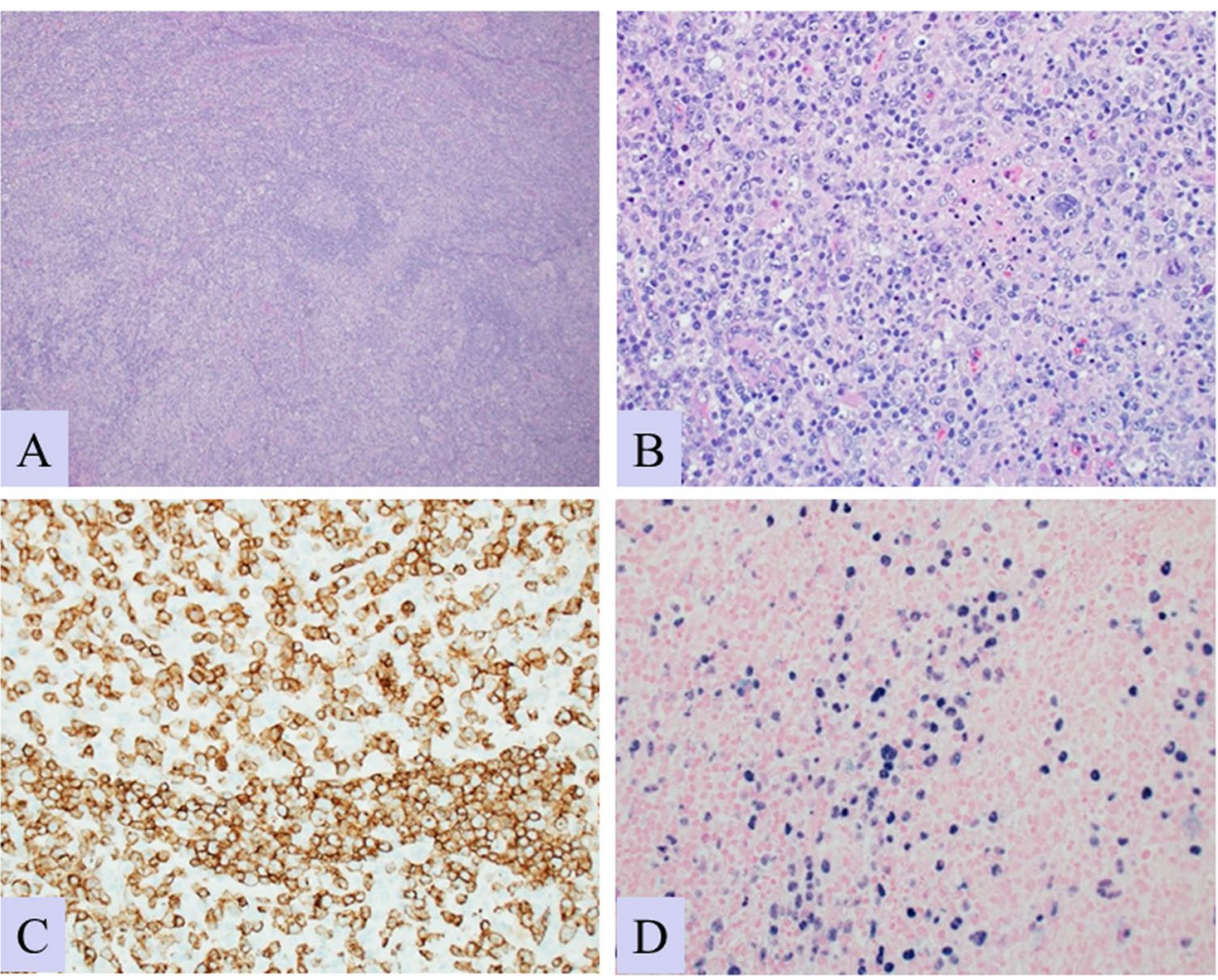
tonsils and adenoids [10]. Although distinguishing IM from Hodgkin and non-Hodgkin lymphomas, ALPS, and other viral lymphadenitides is fairly straightforward when integrating morphologic, immunophenotypic, molecular, and clinical features, the distinction between IM and IM-like PTLD and EBV-positive mucocutaneous ulcer usually requires the correct clinical setting for a definitive diagnosis.

Cat-scratch disease (CSD) is a classic example of necrotizing granulomatous lymphadenitis. It is caused by the bacterium Bartonella henselae, a pleomorphic Gramnegative rod, and is relatively common in children with cervical and supraclavicular lymph nodes frequently involved. As the name of the disease suggests, the causative organism is typically inoculated into the skin of an individual after being scratched by a cat, a useful piece of history if available. Approximately 10-14 days after inoculation, lymphadenopathy develops, occasionally with systemic symptoms including fever, malaise, and loss of appetite, which may prompt a biopsy. The disease is usually self-limited with full resolution occurring after a month with or without treatment [3].

In cat-scratch disease, lymph node architecture is intact but distorted by variably sized granulomas composed mostly of bland histiocytes with occasional epithelioid forms and rare multinucleated giant cells. Early on, the granulomas are mostly subcapsular in location with variable amounts of central neutrophil-rich necrosis and a background of follicular hyperplasia. As the disease progresses, the necrotizing granulomas enlarge and expand into paracortex, forming stellate microabscesses with palisading histiocytes (Fig. 3a and b). Increased numbers of CD123 + plasmacytoid dendritic cells (PDCs) are commonly seen at this point, as is an intrasinusoidal proliferation of monocytoid B-cells [3]. In histologically suggestive cases, the $B$. henselae organisms can sometimes be visualized with a Warthin-Starry or Steiner silver stain; however, the number of organisms may be sparse and in advanced cases may not be present at all. Definitive evidence of infection usually requires positive serological and/or PCR tests for B. henselae.

Several other bacterial organisms, as well as fungal organisms and Mycobacterium species, can cause necrotizing granulomatous lymphadenitis similar to that seen in cat-scratch disease. As a consequence, culture studies and special stains for fungi (e.g., GMS and PAS stains) and acid fast bacilli (e.g., Fite and Ziehl-Neelsen stains) are always a good idea when confronted with a lymph node showing necrotizing granulomas. Despite the diversity of other potential infectious etiologies of necrotizing granulomatous lymphadenitis, in the head and neck lymph nodes of children, infection with one of the many atypical (nontuberculous) mycobacterial species constitutes the main differential diagnosis with cat-scratch disease [11]. Another important infectious differential diagnosis is Toxoplasma lymphadenitis caused by the protozoal organism $T$. gondii. As with cat-scratch disease, $T$. gondii is transmitted by cats and can cause cervical lymphadenopathy in children,
Fig. 3 a, b Necrotizing granulomatous lymphadenitis. a Low-power H\&E view of necrotizing granulomatous lymphadenitis that can be seen in cat-scratch disease including a large "stellate microabscess" at the bottom of the image. $\mathbf{b}$ Higher power H\&E view of the "stellate microabscess" showing palisading histiocytes. c, d. Toxoplasma lymphadenitis. c Low-power H\&E view of Toxoplasma lymphadenitis showing follicular hyperplasia and a proliferation of monocytoid lymphocytes within the subcapsular sinus. d Mediumpower $H \& E$ view of a reactive germinal center from the same lymph node in $\mathbf{c}$ showing several small non-necrotic "microgranulomas" within the germinal center
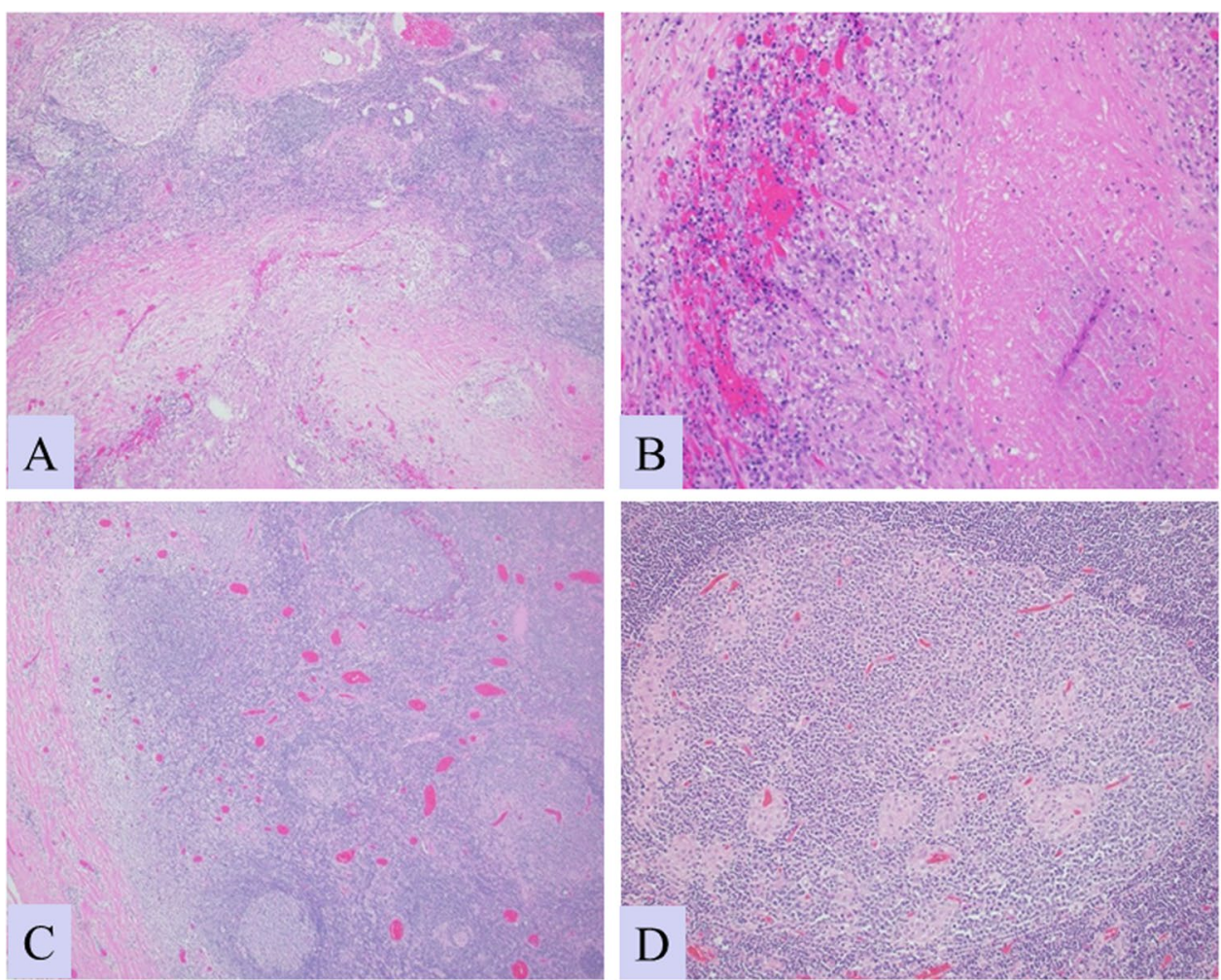
sometimes accompanied by an IM-like illness. Toxoplasma lymphadenitis is characterized by a trio of histologic features that strongly suggest the diagnosis $[12,13]$. These include follicular hyperplasia, intrasinusoidal monocytoid B-cell proliferation, and small clusters of epithelioid histiocytes ("microgranulomas") adjacent to and within reactive germinal centers (Fig. 3c and d). While follicular hyperplasia and intrasinusoidal monocytoid B-cell proliferation are features of both cat-scratch disease and Toxoplasma lymphadenitis, it is the nature of the granulomatous reaction that distinguishes the two in immunocompetent patients: in cat-scratch disease the granulomas are large and necrotizing with associated suppurative inflammation; in Toxoplasma lymphadenitis the granulomas are small without necrosis or inflammation. While the histologic features of Toxoplasma lymphadenitis are highly suggestive of the disease, the diagnosis can be confirmed with serologic and/or molecular studies for $T$. gondii, and, rarely, identification of $T$. gondii cysts on routine stains. Other, non-infectious, differential diagnoses for cat-scratch disease include Kikuchi-Fujimoto disease and certain variants of classic Hodgkin lymphoma; however, distinguishing these entities from cat-scratch disease is typically straightforward on morphologic, immunohistochemical, and/or clinical grounds.

Kikuchi-Fujimoto disease (KFD), also known as histiocytic necrotizing lymphadenitis, is the prototypical example of non-granulomatous necrotizing lymphadenitis. It is a benign self-limited disorder that most commonly presents as isolated cervical lymphadenopathy in young adults and children. The original cases were described in Japan and other Asian countries; however, the disorder is now recognized to occur worldwide. The lymphadenopathy of KikuchiFujimoto disease can be tender or painless, and there are usually associated systemic symptoms such as fever and elevated inflammatory markers in the serum [14]. The cause of Kikuchi-Fujimoto disease is unknown; however, various infectious etiologies have been suggested. An association with autoimmune disease has been described in children [15], and "Kikuchi-like features" are not infrequently present in the lymphadenitis of systemic lupus erythematosus (SLE).

Histologically, Kikuchi-Fujimoto disease is characterized by well-delineated paracortical areas of neutrophilfree necrosis containing abundant karyorrhectic debris and fibrin deposits (Fig. 4a). A foamy macrophage response is usually seen in association with the necrosis; however, discrete granulomatous formations are not a feature. The adjacent non-necrotic paracortex is remarkable for numerous CD123 + PDCs and transformed reactive CD $8+$ T-immunoblasts, the latter of which are believed to mediate the characteristic necrosis of the disease through induction of apoptosis [16]. The remaining lymph node tissue shows normal appearing architecture. Occasional reactive germinal centers can be seen, but follicular hyperplasia is not a typical feature. In early lesions of Kikuchi-Fujimoto disease necrosis may be minimal or absent. Instead, focally prominent proliferations of paracortical PDCs and transformed
Fig. 4 Kikuchi-Fujimoto disease. a Medium-power $H \& E$ view of an early lesion of Kikuchi-Fujimoto disease showing a paracortical proliferation of large immunoblastic and plasmacytoid mononuclear cells. b High-power H\&E view of the paracortical neutrophilfree necrosis characteristic of Kikuchi-Fujimoto disease showing abundant karyorrhectic debris and fibrin deposition. c, $\mathbf{d}$ Medium-power views of immunohistochemical stains for CD123 (c) and CD8 (d) showing numerous $\mathrm{CD} 123$ + plasmacytoid dendritic cells and CD8 + T-immunoblasts in an early lesion of Kikuchi-Fujimoto disease
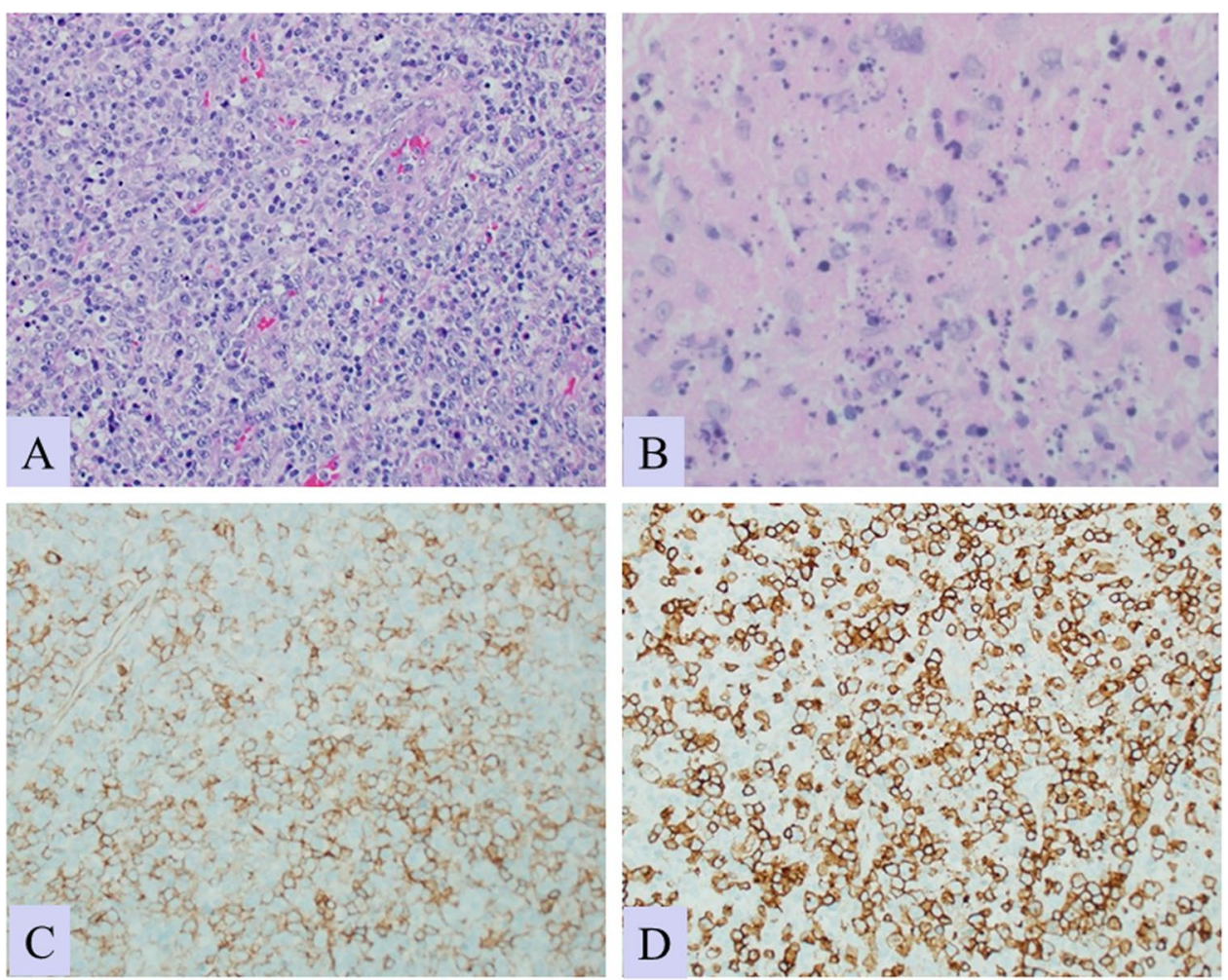
CD8 + T-immunoblasts occur (Fig. 4b-d), which can morphologically mimic a large cell lymphoma [17]. The mixed nature of this population of cells and its focal nature in an otherwise normal appearing lymph node help distinguish early Kikuchi-Fujimoto disease from large cell lymphoma. Another differential diagnosis with Kikuchi-Fujimoto disease is necrotizing granulomatous lymphadenitis of the type previously described in cat-scratch disease. The lack of discrete granulomatous formations and the neutrophilfree nature of the necrosis in Kikuchi-Fujimoto disease help distinguish these two entities. Finally, various viral lymphadenopathies and the lymphadenopathy associated with SLE can have overlapping features with Kikuchi-Fujimoto disease. In these cases, clinical history and/or specific laboratory studies for viral agents or SLE can help make a more refined diagnosis.

\section{Lymphoma}

Lymphoma comprises $10-15 \%$ of childhood malignancy, and the frequency of lymphoma from the SEER database is $0.5-1.2$ per 100,000 [18]. Although any type of lymphoma can occur in a child, most pediatric lymphomas comprise only a few of the subtypes as defined by the World Health Organization [19]. Aggressive lymphomas such as Burkitt lymphoma, diffuse large B-cell lymphoma, and ALK + anaplastic large cell lymphoma are much more common than indolent lymphomas. In the head and neck of adults, lymphoma is the third most common malignancy after squamous cell carcinoma and salivary gland tumors, and it comprises $5 \%$ of head and neck neoplasms [20]. Head and neck lymphomas most often involve cervical lymph nodes, but extranodal lymphomas also occur including bone, skin, nasal, oral and para oral lymphomas [21].

Classic Hodgkin lymphoma (CHL) makes up 3\% of all pediatric malignancies, although it is more common in young adults and has a second peak in late adulthood. In children less than 5 years old, it is exceedingly rare, but is the most common hematopoietic neoplasm in the 15-29 yearold age group. Equally involving boys and girls at young ages, CHL is more common in men in adults. The prognosis of children with CHL appears to be the same as in older populations. Keegan THM et al. found that EBV positive cases are associated with better outcomes in young patients, but this has not been substantiated in other studies [22, 23]. Comprising $4 \%$ of head and neck lymphomas, CHL involves cervical lymph nodes when it arises in the head and neck and is infrequently extranodal, where it can involve the thyroid, parotid gland, nasopharynx and Waldeyer ring [24]. Painless neck lymphadenopathy is the most frequent presentation of pediatric head and neck CHL. In a recent study looking at head and neck lymphoma in Iran in both children and adults, 200 of the 500 cases are classic Hodgkin lymphoma, demonstrating its prevalence as a head and neck tumor [25]. Subtypes of CHL include nodular sclerosis (NSCHL), mixed cellularity (MCCHL), lymphocyte rich (LRCHL) and lymphocyte depleted (LDCHL). NSCHL is most common in adolescents and young adults (ages 15-34) and the most common type detected in the head and neck. MCCHL is much more likely to express Epstein Barr virus markers such as EBER as compared to NSCHL or LRCHL. LDCHL is the least likely type to involve the head, where it is found in only $1 \%$ of cases. Quiñones-Avila et al. indicated that LRCHL may be the most common subtype in Waldeyer ring [26]. Older studies conflict with Quiñones-Avila et al. and report MCCHL as the most common CHL subtype involving Waldeyer ring; however, LRCHL may not have been considered a subtype of CHL in some older studies [27,28].

CHL is a lymphoma of B-cell origin, characterized by Hodgkin Reed-Sternberg cells (HRS) and variants occurring in a benign usually mixed inflammatory background (Fig. 5a, b). The HRS cells are typically seen singly and scattered, and not in large clusters. The background inflammatory milieu includes small lymphocytes, eosinophils, histiocytes, neutrophils and plasma cells. HRS cells are large, sometimes binucleate, with multilobate nuclei and distinct eosinophilic macronuclei. Flow cytometry does not reveal a monoclonal B-cell population; however immunohistochemistry shows that the HRS cells are typically CD30(+), CD15( \pm ) (Fig. 5c, d), PAX5(+), CD20( \pm ), CD45rb(-), EBER ISH $(-/+)$ and MUM1(+). EBV may be more prevalent in Waldeyer ring CHL as compared to nodal CHL [28].

Nodular lymphocyte predominant Hodgkin lymphoma (NLPHL) is a different lymphoma distinct from CHL which can present as a mas in older teens and can be found in the head and neck (most likely in cervical lymph nodes). The malignant cells of NLPHL are LP cells, which are single scattered large cells often with polylobate nuclei resembling a kernel of popcorn (popcorn cells). LP cells are typically ringed by PD1 + T-cells. LP cells are positive for CD20, OCT2, CD79, PAX5, BOB1 and CD45rb. NLPHL can also involve Waldeyer ring [29].

Burkitt lymphoma (BL) (Fig. 6) is a non-Hodgkin B-cell lymphoma that most commonly occurs in children and young adults. Characterized by monomorphic intermediate sized B-cells with basophilic cytoplasm, a high Ki-67 proliferation index, variable EBV infection, and a $M Y C$ gene translocation, BL has an aggressive clinical course and was first described by Denis Burkitt in the 1950s [30]. There are three clinical variants: the endemic BL variant, the sporadic BL variant, and the immunodeficiency-associated BL variant. Endemic BL is found in equatorial Africa and Papua New Guinea, where it is the most common childhood malignancy, occurring most often in children 4-7 years of age and usually in the jaw. Sporadic BL has more of a worldwide 
Fig. 5 Classic Hodgkin lymphoma; lymph node from the left neck of a 17-year-old male. a The lymph node is effaced by a nodular lymphoid proliferation. The capsule is thickened. b Residual follicle with numerous large atypical Hodgkin-ReedStenberg (HRS) cells. HRS cells show positivity for $\mathbf{c} \mathrm{CD} 30$ and d CD15

Fig. 6 Burkitt lymphoma. a Proliferation of monomorphic intermediate sized cells showing a starry sky appearance. b CD20 positivity c High Ki-67 proliferation index of $\sim 99 \%$. d Break apart MYC FISH study showing fused yellow signals and separate green and red signals indicative of a $M Y C$ gene rearrangement
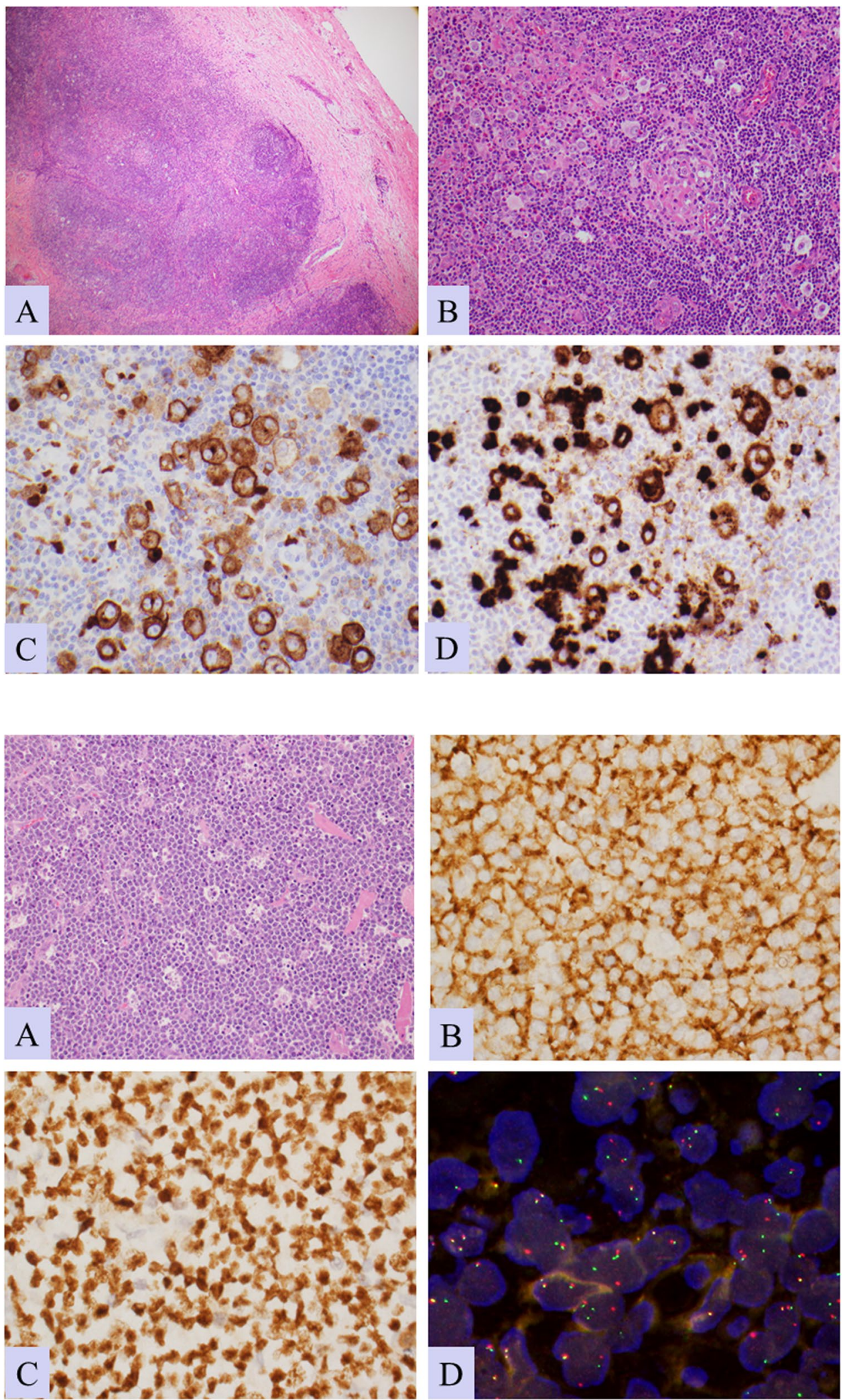

distribution, and it develops mostly in children and young adults. Although it only accounts for 1-2\% of lymphoma in the USA and western Europe, BL comprises $30-50 \%$ of all lymphoma occurring in children in these countries. $\mathrm{BL}$ is frequently an extranodal disease and may involve the head and neck. In endemic BL, $\sim 50-70 \%$ of cases involve the jaw 
or other facial and orbital bones but can also involve other extranodal sites including the thyroid, nasopharynx, maxilla, sphenoid, and salivary glands. Sporadic BL more typically involves the ileocecum, but facial tumors and Waldeyer's ring involvement have been infrequently reported. Breast can also be involved at the beginning of puberty, during pregnancy, or during lactation. Lymph node involvement of BL is uncommon, especially in children. Symptoms for cases in the head and neck may include jaw swelling, jaw pain, nasal obstruction, facial swelling, headache, and proptosis.

The intermediate sized tumor cells of BL have nuclei with fine clumped chromatin, multiple distinct nucleoli, and deep basophilic cytoplasm which sometimes contains lipid vacuoles. Frequently, numerous tingible body macrophages are present, which impart a low-power "starry sky" appearance on H\&E. The tumor cells will express B-cell markers, germinal center markers (CD10 and BCL6), MYC protein, and TCL1 (most pediatric cases), but BCL2 is usually negative or only weakly/partially positive. The Ki-67 proliferative index is high, usually close to $100 \%$. Children tend to show a typical phenotype, but older patients may express aberrant phenotypes such as cases lacking CD10 or expressing CD5 or TDT. MYC translocations are characteristic for BL. These translocations involve the $M Y C$ gene on chromosome 8q24, which most commonly partners with the $I G H$ gene on chromosome $14 \mathrm{q} 32(\sim 80 \%$ of cases) and less commonly with $I G K$ on chromosome $2 \mathrm{p} 11$ or $I G L$ on chromosome $22 \mathrm{q} 11$. Translocations involving the $B C L 2$ gene such as $\mathrm{t}(14 ; 18)$ (q32; 21$) / I G H-B C L 2$ and the $B C L 6$ gene on chromosome $3 q 27$ should not be detected in BL, or else the lymphoma would be reclassified as a "double/triple" hit lymphoma which falls under the category of high-grade B-cell lymphoma with $M Y C$ and $B C L 2$ and/or BCL6 rearrangements. Other gene mutations have been identified in BL and next generation sequencing studies have shown the importance of the B-cell receptor signaling pathway in BL including $T C F 3, I D 3$, and $C C N D 3$. ID 3 functions as an inhibitor of $T C F 3$, so mutation of ID3 leads to increased TCF3 activity [31]. Table 1. Some differences have been noticed in the genetic alterations of children as compared to adults. Havelange et al. found that children show less 13q31.3q32.1 amplification, less 7q32q36 gain, less ID3 mutation, and that only adults showed 18q21.3 loss of heterozygosity [32]. Alterations in chromosome 17 maybe a more favorable prognostic marker and alterations in chromosome $22 q$ and $13 q$ less favorable prognostic markers in children as compared to adults.

$\sim 5 \%$ of cases with morphologic and phenotypic features of BL do not show MYC translocations. At least some of these cases would currently be classified as Burkitt-like lymphoma with 11q aberration (BLL w11q). This is a newly recognized lymphoma which is a provisional entity in the World Health Organization 2016 Classification of Tumors
Table 1 Gene alterations/translocation in Burkitt lymphoma

\begin{tabular}{lll}
\hline Genes & Translocation & Prevalence \\
\hline$I G H$ at $14 \mathrm{q} 32, M Y C$ at $8 \mathrm{q} 24$ & $\mathrm{t}(8 ; 14)$ & $80 \%$ \\
$I G K$ at $2 \mathrm{p} 11, M Y C$ at $8 \mathrm{q} 24$ & $\mathrm{t}(8 ; 22)$ & $15 \%$ \\
$I G L$ at $22 \mathrm{q} 11, M Y C$ at $8 \mathrm{q} 24$ & $\mathrm{t}(2 ; 8)$ & $5 \%$ \\
$T C F 3$ & & $\sim 40 \%$ of endemic \\
& & $\mathrm{BL}, \sim 70 \%$ sporadic \\
& & $\mathrm{BL}$ \\
CCND3 & $33 \%$ \\
\hline BD & & $15 \%$ \\
\hline
\end{tabular}

$B L$ Burkitt lymphoma

of Haematopoeitic and Lymphoid Tissues. BLL w11q can occur in children and can involve the head and neck, being reported in both the tonsil and submaxillary region. These cases show proximal gains and telomeric losses on chromosome 11q. BLL w11q resembles BL morphologically, but can show more pleomorphism, more lymph node involvement, and more of a follicular growth pattern. Cytogenetic testing has shown a more complex karyotype as compared to BL. BLL w11q shows BTG2, DDX3X, ETS1, EP300, and GNA13 alterations, but lacks the ID3,TCF3, and CCND3 mutations of BL, suggesting that BLL w $11 \mathrm{q}$ is genetically a different disease than BL [33].

The differential diagnosis of BL almost always includes diffuse large B-cell lymphoma. (DLBCL). Although $\mathrm{BL}$ is sometimes thought of more of a pediatric disease, DLBCL is actually more common in kids, and is the most common nonHodgkin lymphoma from ages 15 to 29. It is more frequent in boys and has a better prognosis in children, even though it presents at a higher stage as compared to adults. Head and neck, mediastinum, and gastrointestinal tract are the most common sites of involvement. Pediatric DLBCL has the same morphology as the adult lymphoma counterpart consisting of intermediate to large sized B-cells with a diffuse growth pattern. Pediatric DLBCL differs from adult DLBCL with an increased prevalence of germinal center phenotype (increased CD10). Germinal center type DLBCL has a better prognosis than non-germinal center DLBCL, which correlates with the better survival in pediatric DLBCL. BCL2 immunostaining is more often negative in pediatric DLBCL and increases with the age of the patient [34].

Molecular alterations in $M Y C, B C L 6$, and $\mathrm{t}(14 ; 18)$ may be seen in pediatric DLBCL, similar to adult DLBCL, although $\mathrm{t}(14 ; 18)$ and $B C L 6$ rearrangements are less common in kids. Early studies suggested that $M Y C$ rearrangement may be increased in pediatric DLBCL and associated with a worse prognosis; however, Szczepanowski et al.'s recent study utilizing gene expression arrays did not find an increase in $M Y C$ rearrangement [35]. High grade B-cell lymphoma with MYC and BCL2 and/or BCL6 
rearrangements is extremely rare in the pediatric population, but has been reported in an HIV + child [36].

Cases of diffuse large B-cell lymphoma that show strong MUM1 expression by immunohistochemistry and IRF4 molecular rearrangements should be reclassified as large B-cell lymphoma with IRF4 rearrangement (LBCL w IRF4). These cases often occur primarily in the pediatric population and most commonly involve the head and neck including Waldeyer ring. The median patient age is 12 , although the range is from 4 to 79 years [37]. The tumor can have follicular or diffuse growth patterns, and the tumor cells can look similar to DLBCL, NOS or may have a more blastic morphology. In addition to MUM1 being positive, most cases have a germinal center phenotype, expressing either BCL6, CD10, or both (Fig. 7). In cases of a large B-cell lymphoma showing a follicular growth pattern, the presence of triple positive immunohistochemical staining (MUM1 +, CD10+, BCL6+) should prompt molecular testing for an IRF4 rearrangement to rule out the possibility of LBCL w IRF4. The Ki-67 proliferative rate is often high and does not show polarization in follicular areas. Some cases show BCL6 gene rearrangement, but they usually lack $M Y C$ or $B C L 2$ rearrangement. LBCL w IRF4 has a different gene expression profile than pediatric DLBCL showing mutations in NF- $\kappa \mathrm{B}$ pathway genes (CARD11, CD79B, and MYD88), as well as gains of chromosome 7 and 11q12.3-q25 and losses of 17p13 [38]. LBCL w IRF4 typically responds well to combination immunochemotherapy with or without radiation and has an excellent prognosis.

While pediatric lymphomas of the head and neck are most commonly of B-cell origin, T-cell lymphomas can also occur. Anaplastic large cell lymphoma (ALCL) is a mature T-cell lymphoma that commonly effects children and young adults. It represents $10-15 \%$ of all pediatric nonHodgkin lymphoma and 30-40\% of all large cell lymphomas in children. ALCL has a mean age of 22 years and has been reported in patients as young as 3. Classification of ALCL divides it into 3 different lymphomas: ALK positive anaplastic large cell lymphoma (ALK + ALCL), ALK negative anaplastic large cell lymphoma (ALK- ALCL), and primary cutaneous anaplastic large cell lymphoma (PCALCL), which is reserved for cases that originate in the skin. All three types of ALCL can involve the head and neck. PCALCL involves the head and neck in $\sim 40 \%$ of cases and is most often found on the scalp. Secondary involvement of the scalp by systemic ALCL is rare so most of these scalp lesions are PCALCL.

ALK + and ALK-ALCL are both systemic lymphomas that can involve cervical lymph nodes and are separated from one another by the presence or absence of an $A L K$ gene rearrangement, which can be detected by immunostaining for the ALK protein. The tumor cells of ALCL, regardless of subtype, are variably sized with irregular shapes often with polylobate nuclei. Hallmark cells can sometimes be seen in ALCL, which are large cells with multiple nuclei that are horseshoe or kidney shaped. ALCL is of T-cell lineage with
Fig. 7 Large B cell lymphoma with IRF4 rearrangement; palatine tonsil from a 12-year-old male. a Large back to back follicles with absent mantle zones. b Monotonous intermediate to large sized lymphoid cells. The cells are CD20 positive (not shown), c CD10 positive, and $\mathbf{d}$ MUM1 positive
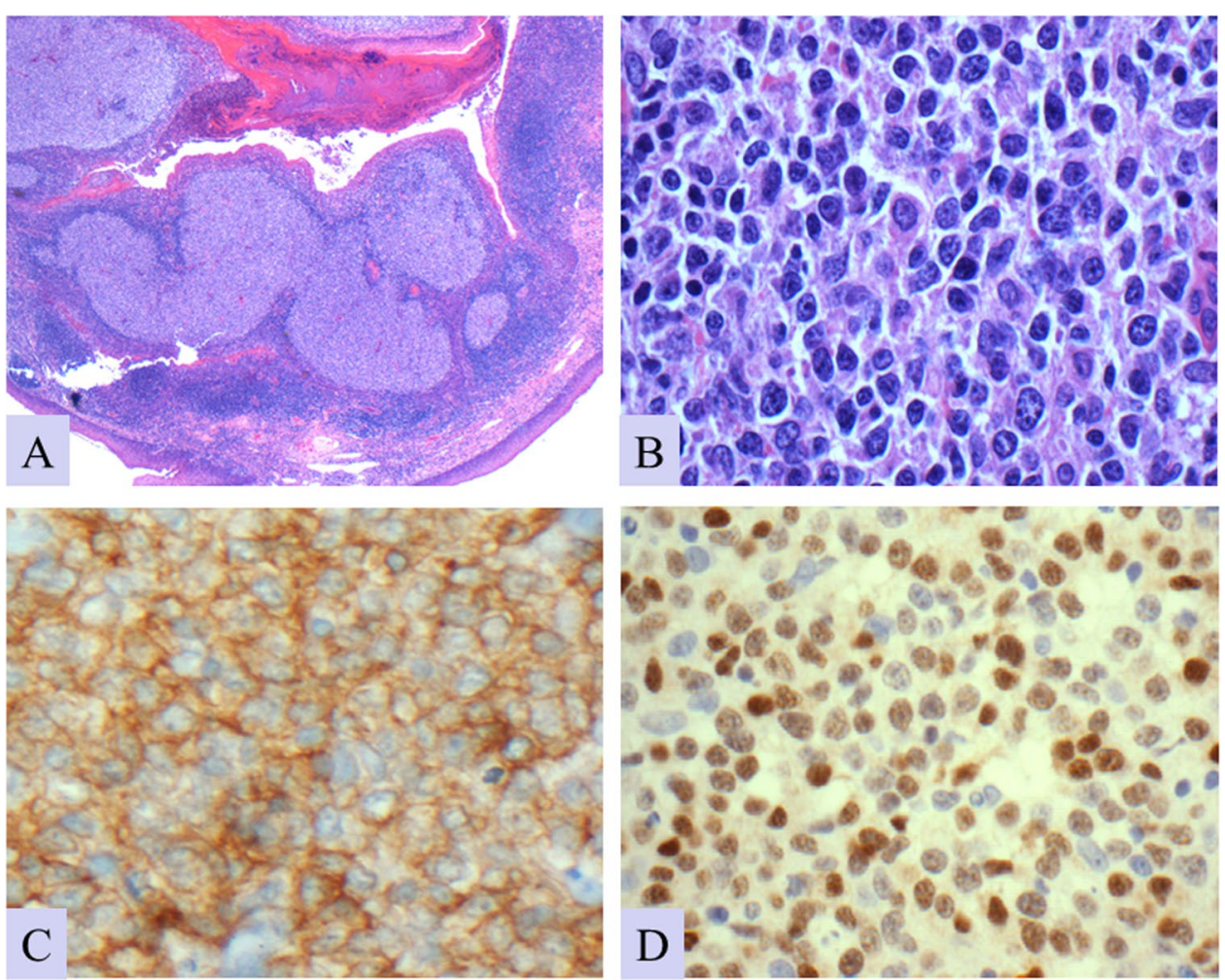
monoclonal T-cell receptor gene rearrangements in almost all cases. Immunophenotypically, ALCL always expresses strong CD30 in the vast majority of tumor cells, a feature needed for the diagnosis. Most cases also express one or more T-cell-related antigens, most commonly CD4; however, cases lacking T-cell marker expression, so-called "null type" ALCLs, are well described. Other markers that can be expressed in ALCL include CD25, CD43, EMA, and cytotoxic markers.

Pediatric ALCLs are more frequently ALK $+(90 \%$ of cases) than adult ALCL. Nguyen KA, et al. found that ALK + ALCL was found in the head and neck in $10 \%$ of cases and that these cases have a better survival outcome as compared to CNS or thoracic cases [39]. The most common gene rearrangement in ALK + ALCL ( $75 \%$ of cases) is the $\mathrm{t}(2 ; 5)$ translocation involving the $A L K$ gene on chromosome $2 \mathrm{p} 23$ and the NPM gene on chromosome $5 \mathrm{q} 35$. This rearrangement corresponds to a characteristic diffuse nuclear and cytoplasmic ALK protein immunohistochemical staining pattern in tumor cells. Variant translocations that involve $A L K$ and several other partner genes are known to occur in the other $25 \%$ of cases, some of which also have characteristic immunohistochemical staining patterns. $A L K$ rearrangements are not found in ALK- ALCL and only very rarely in PCALCL. TP63 (adverse prognostic marker) and DUSP22 (favorable prognostic marker) are genes that are not infrequently rearranged in ALK- ALCL, but these are only rarely detected in pediatric patients.

Fig. 8 Pediatric follicular lymphoma; cervical lymph node from a 4-year-old male. a Effacement of the lymph node architecture by irregular neoplastic follicles. b Large expansible follicles showing attenuation of the mantle zones. c The follicles show a monomorphic population of intermediate sized blastoid cells with interspersed tingible body macrophages. d CD10 staining the germinal center. e Negative BCL2 staining. f High Ki-67 proliferation index
Small B-cell lymphoma occur less frequently in the pediatric age group as compared to the large cell lymphomas previously discussed. Follicular lymphoma $(F L)$ and pediatric-type follicular lymphoma (PTFL) (Fig. 8) are two different lymphomas in current classifications, and a child can be diagnosed with either type of lymphoma in the head and neck (Table 2). In children diagnosed with lymphoma, follicular lymphoma is the diagnosis in only $1-2.5 \%$ of cases. However, in the adolescent and young adult age group (15 to 39 years old) it accounts for 15-20\% of lymphomas. Childhood FL is more often detected in boys and has an increased prevalence as the child's age increases [40]. FL of the head and neck frequently involves cervical lymph nodes, but can involve any location including the thyroid, nasopharynx, sinuses, parotid gland, and submandibular gland. When it is a primary presentation in the skin, it should be diagnosed as primary cutaneous follicle center lymphoma. FL is a usually low-grade B-cell neoplasm in which the neoplastic cells express germinal center markers (CD10, BCL6, HGAL, LMO2), as well as frequent BCL-2. Most cases exhibit a follicular growth pattern defined by the presence of follicular dendritic cell meshworks positive for CD21, CD23, and CD35; however, diffuse growth patterns also occur. The $\mathrm{t}(14 ; 18)($ $\mathrm{q} 32 ; \mathrm{q} 21) I G H-B C L 2$ rearrangement is detected in $80-90 \%$ of cases of FL, but is not specific to FL. FL in children tends to have a better prognosis than in adults, lower stage, lower grade, and more frequent BCL2 expression.

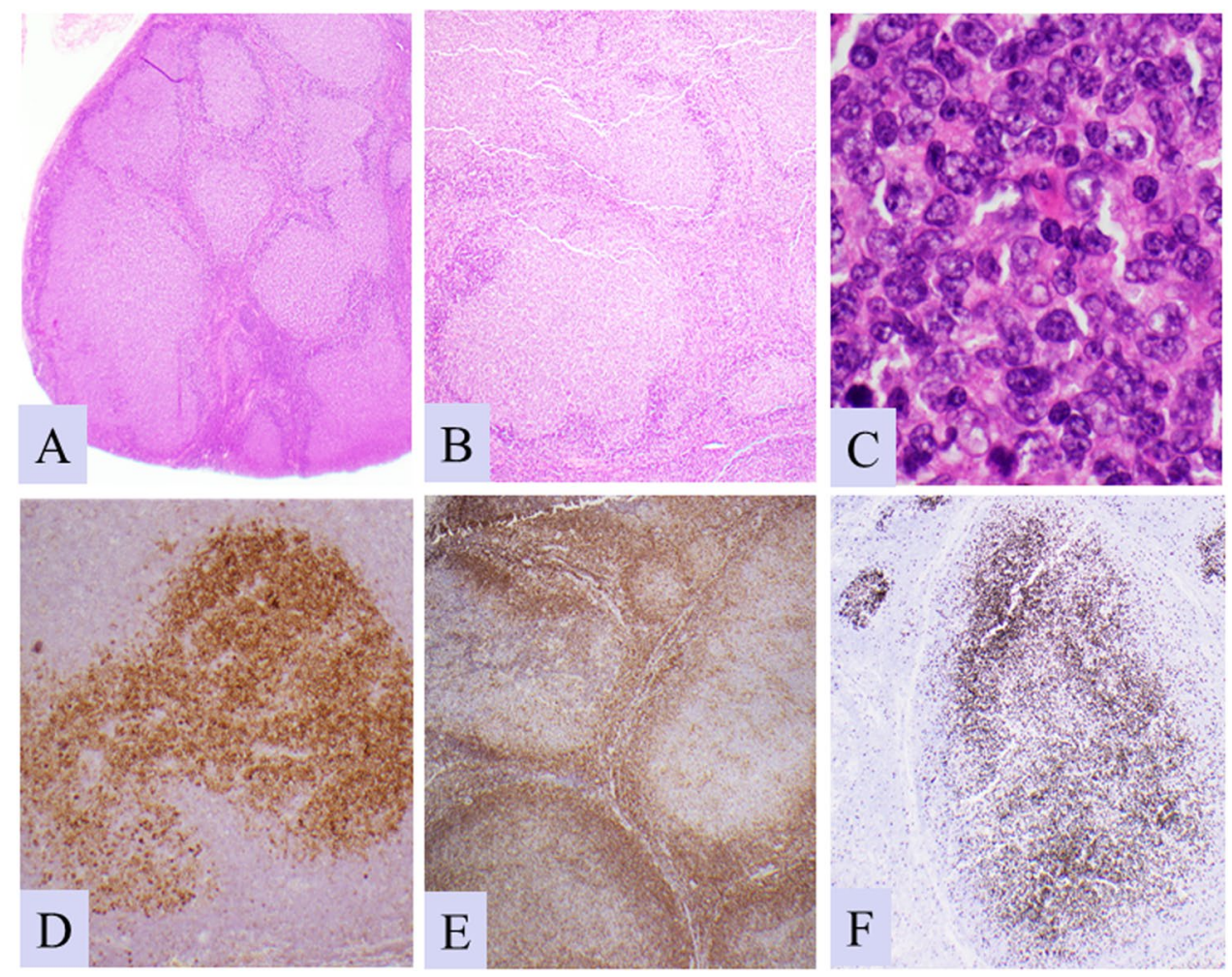


Table 2 Pediatric-type follicular lymphoma versus usual follicular lymphoma

\begin{tabular}{lll}
\hline & PTFL & FL \\
\hline Morphology & Serpiginous follicles, blastoid cells & $\begin{array}{c}\text { Back to back follicles, } \\
\text { centroblasts and cen- } \\
\text { trocytes } \\
\text { BCL2 IHC }\end{array}$ \\
FISH testing & Usually negative or weakly + & BCL2 rearrangements in \\
& No BCL2, BCL6 or MUM1 /IRF rearrange- & $80 \%$, BCL6 rearrange- \\
Other mutations & ments & ments in 15\% \\
Sex & TNFRSF14 and MAP2K1 & CREBBP, KMT2D \\
Treatment & Marked male predominance & Less male predominance \\
\hline
\end{tabular}

$P T F L$ pediatric-type follicular lymphoma, $F L$ follicular lymphoma
Pediatric-type follicular lymphoma (PTFL) is recognized as a distinct entity in the current WHO lymphoma classification. It characteristically presents at a limited stage, with a high-grade histological appearance, but very indolent behavior. It primarily occurs in children and young adults, reported in children as young as 3 years old with a median age range of $15-17$. There is a strong male predominance with a male:female ratio of $10: 1$. The prognosis is excellent, and it is considered curable in most cases with a 5 -year survival of $>95 \%$ even with surgical excision as the only treatment. It most frequently involves the lymph nodes of the head and neck, but also tonsils and Waldeyer ring. It has been reported in cervical, periparotid, postauricular, submandibular, and submental lymph nodes, where it typically presents as an isolated nodule. By morphology, PTFL shows large expanded sometimes serpiginous follicles often containing tingible body macrophages. There may be a monotonous population of intermediate sized blastoid cells with indistinct nucleoli in the follicles. Unlike typical FL, grading is not used for PTFL, although most cases would be considered high grade under the grading system for usual FL. Germinal center markers should be positive, but BCL2 is commonly negative with expression seen in only $30 \%$ of cases, which is typically weak. Table 2. FOXP1 is also recently reported to be positive in PTFL, and a useful marker in differentiating PTFL from reactive follicular hyperplasia [41]. The proliferative rate by $\mathrm{Ki}-67$ is high (>30\%) and does not show the normal polarization seen in reactive germinal centers. Monoclonal $I G H$ gene rearrangements can be detected in PTFL, but BCL2, BCL6, and IRF4 rearrangements are not found. If one or more of these genes are arranged, then another diagnosis should be considered. Other molecular alterations that have been identified in PTFL include 1p36 loss of heterozygosity, TNFRSF 14 mutation, MAP2K1 mutation, and gains/amplification of 6pter-p24.3. The presence of TNFRSF 14 and MAP $2 K 1$ mutations, as well as the lack of epigenetic modifiers (CREBBP, KMT2D), distinguish PTFL from FL.
Nodal marginal zone lymphoma (NMZL) (Fig. 9) is uncommonly found in the pediatric population. Pediatric NMZL shows a strong male predominance with a male: female ratio of 20:1, and usually presents in the head and neck region. There is typically only localized lymphadenopathy, a low rate of recurrence after treatment, and an excellent prognosis. By morphology, pediatric NMZL usually shows a marginal zone growth pattern with malignant B-cells surrounding reactive germinal centers. The follicles are typically enlarged with small B-cells infiltrating the germinal centers. The phenotype of pediatric MZL is similar to other NMZLs. The lymphoma consists of B-cells expressing CD20 and coexpressing CD43 and BCL2, but negative for germinal center markers and CD5. Expanded follicular dendritic cell meshworks can be seen on stains for CD21, $\mathrm{CD} 23$ and/or CD35. IgD can be used to highlights disrupted/ expanded mantle cell zones, but the lymphoma B-cells are IgD negative. The same molecular alterations are identified in pediatric NMZL as in the common type of NMZL, but the molecular alterations are less frequent in the pediatric type. Molecular testing demonstrates trisomy 18 in only $20 \%$ of cases and trisomy 3 is rare [42].

\section{Histiocytoses}

Histiocytoses are rare neoplasms or tissue proliferations of cells characterized by macrophage, dendritic cell, or monocytic origin. There is a wide range of clinical manifestations. The first attempt at classification in children occurred in 1987 by the Histiocyte Society [43]. The overall incidence of histiocytoses in the United States is $0.142 / 100,000$ persons per annum [44]; this includes a spectrum of entities from acute monocytic leukemias to solid tumor histiocytoses. Children $<1$-year-old have the highest incidence, followed by those $1-4$ years-old and $10-14$ years-old. The largest group of malignancies in head and neck children under 2 years of age was Langerhans Cell Histiocytosis before 1990 [45]; however, newer classification schemes 
Fig. 9 Nodal marginal zone lymphoma; cervical lymph node from a 14 year-old-male. a Low-power view showing vague nodularity. b Effaced architecture with lack of germinal centers. c Monotonous small lymphocytes with clear cytoplasm. d CD20 positivity. e CD21 stain showing infiltration of the neoplastic cells into the follicles. f BCL-6 + residual germinal center cells dispersed by the neoplastic cells
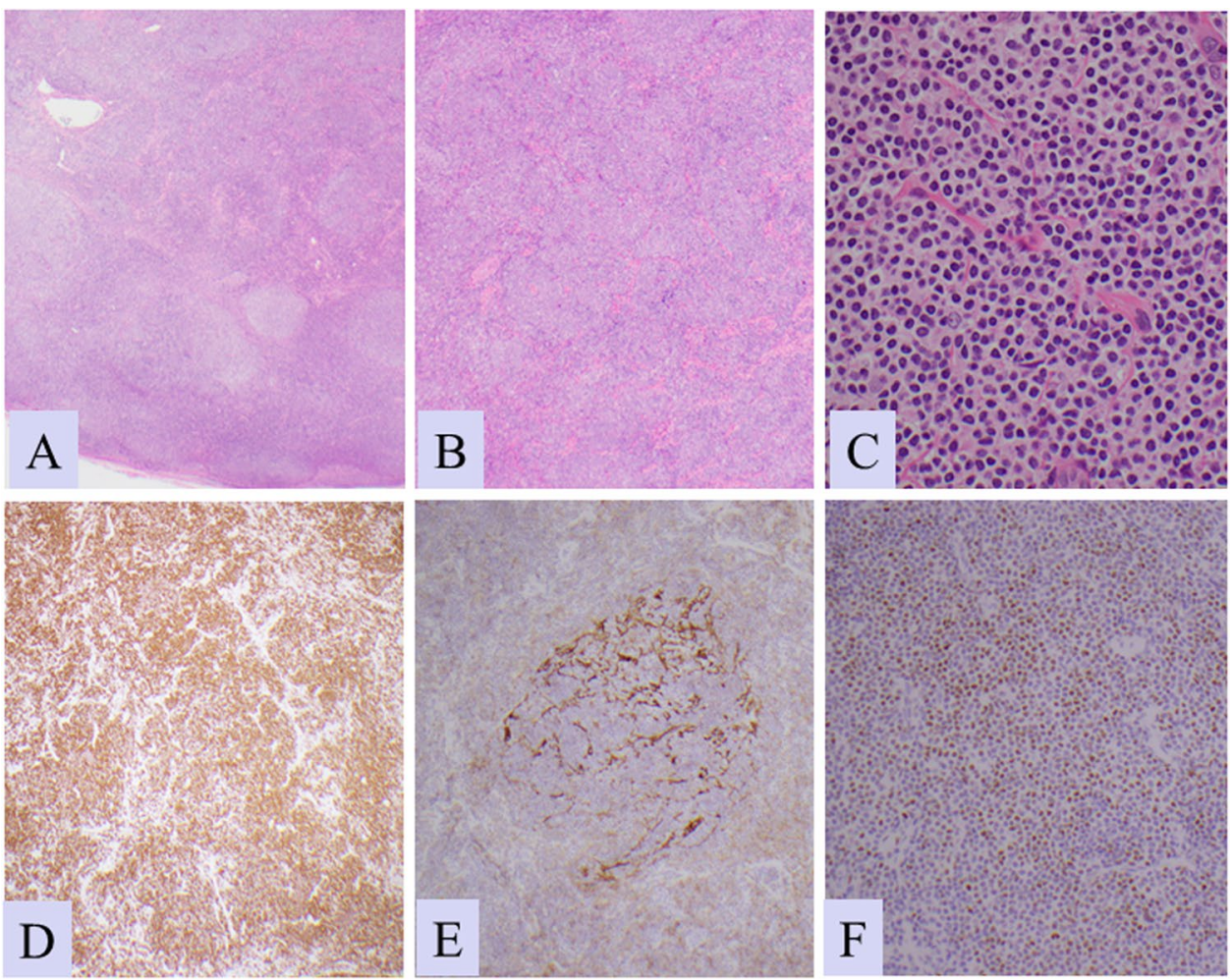

make comparison to the older literature difficult [46]. As do the confusing terms such as "miscellaneous lymphoreticular neoplasms," a category sometimes used when reporting these childhood neoplasms [47]. New modalities for determining clonality such as gene mutation studies show that many histiocytoses once thought to be benign or reactive are in fact clonal [46]. Histiocytoses can be separated into Langerhans cell disorders and non-Langerhans cell disorders (macrophage like) [46, 48].

Langerhans cell histiocytosis ( $\mathrm{LCH}$ ) (Fig. 10a-c) is probably the most consistently recognized and documented of the histiocytoses. LCH is a clonal histiocytosis characterized by CD1a and CD207 (Langerin) positivity, as well as S100 and CD68. Histologically, the cells are mononuclear with abundant slightly eosinophilic cytoplasm and characteristic longitudinally grooved or coffee-bean shaped nuclei [46]. An inflammatory background of eosinophils, small lymphocytes, multinucleated giant cells, and to a lesser degree, neutrophils is present. Nuclear atypia is usually minimal. Ultrastructurally, Birbeck granules are present in the cells, but confirmation by electron microscopy is now seldom performed as immunohistochemistry is considered diagnostic. Langerhans cell sarcoma (LCS) is rarely reported in children and is differentiated from LCH by overtly malignant cytology. Approximately $50 \%$ of $\mathrm{LCH}$ harbor the $B R A F$ V600E somatic mutation [48]. Of the $B R A F$ negative cases, $50 \%$ have $M A P 2 K 1$ mutations. $\mathrm{LCH}$ is the most common histiocytosis in children, and has a spectrum of clinical presentations from an isolated single lesion (single system) to multisystem involvement (two or more sites). The three most common sites of involvement in children include bone (79\%), skin $(36 \%)$, and pituitary gland $(25 \%)$. Of the bone and skin lesions, skull and scalp are the most common anatomic locations in kids [49]. Other less common sites of involvement include mandible, orbit, parotid, cervical lymph node, pituitary, and oral cavity [48, 50, 51]. In the head and neck, the most common presenting sign is unifocal involvement in the skull. In the skin, manifestations include seborrheic dermatitis like eruptions, erythematous crusted, scaly papules, and eczematous lesions, most common on the scalp. The most common manifestation of pituitary gland involvement is central diabetes insipidus [49].

Juvenile Xanthogranuloma (JXG) (Fig. 10d-f) is the most common of the non- $\mathrm{LCH}$ in children with a median age of 2 years. Congenital cases have also been described [52]. The incidence is 1 case per 1 million children, and there is a male predominance. JXG has been associated with neurofibromatosis (NF1) and juvenile myelomonocyte leukemia (JMML). JXG is characterized by cells that are small and oval to spindled without grooves and with pink cytoplasm. Touton giant cells are often present, but less common in the non-dermal sites. Focal xanthomatous change can be seen. Immunohistochemical studies show the cells are strongly positive for CD68 and CD163, variably positive for Factor XIIIa, and uncommonly express S100. CD1a and CD207 are negative, which differentiates JXG from LCH. Genetic 
Fig. 10 a-c Langerhans cell histiocytosis; cervical lymph node from a 2 year-old-female. a Extensive replacement of the lymph node architecture. b Histiocytic cells with longitudinal grooves and eosinophils in the background. c CD1a positivity. d-f Juvenile Xanthogranuloma; soft tissue mass of the neck from a 2-year old. d Mass with overlying skin. Inset shows a touton giant cell. e Histiocytic cells which are slightly spindled. There are several mitoses in this section. $\mathbf{f ~ S 1 0 0 ~ i s ~}$ diffusely positive
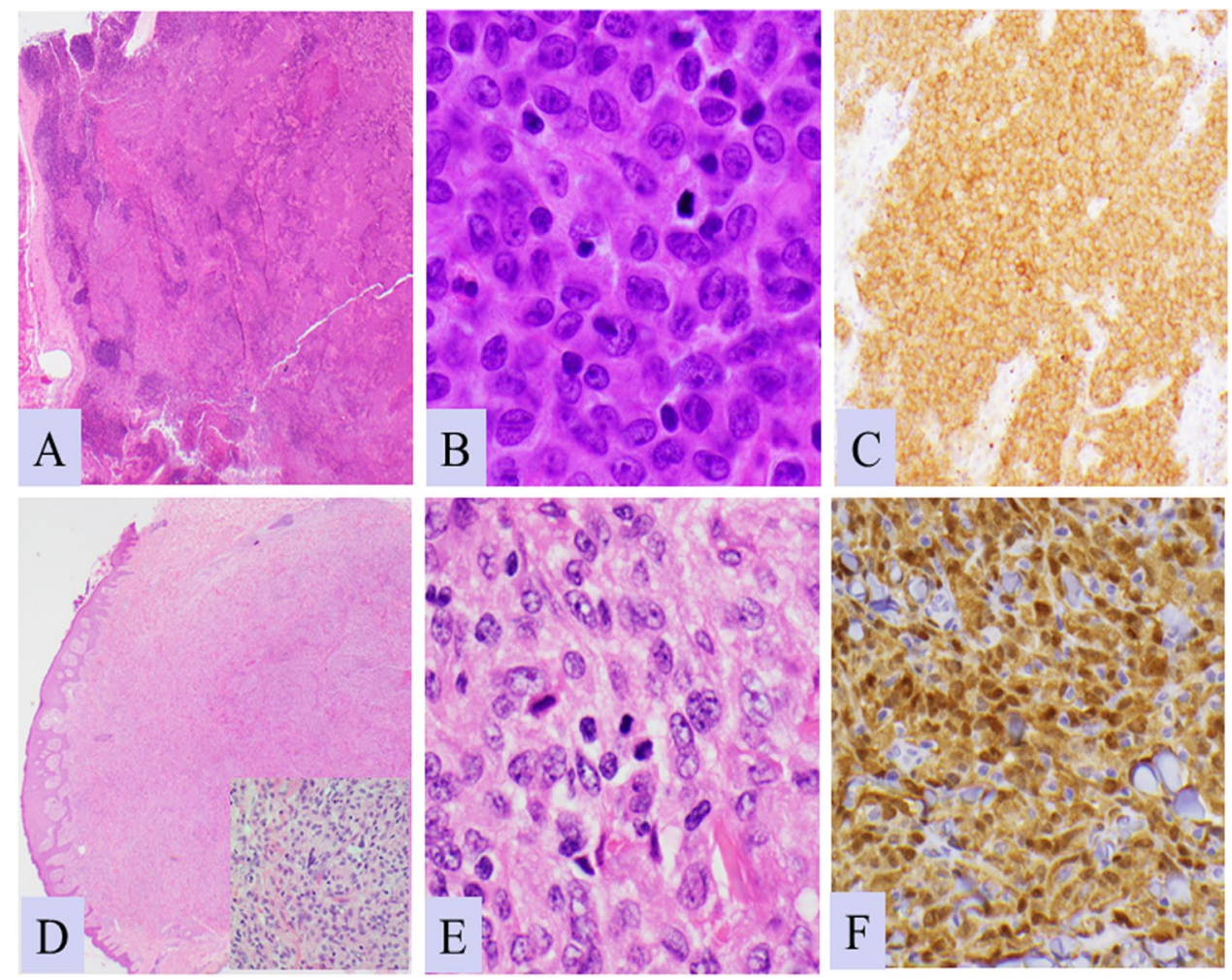

studies show rare mutations in $\mathrm{JXG}$, but no cases with $B R A F$ V600E mutations. JXG is most commonly seen in the skin or face of the head and neck, and can occur in the oral cavity $[52,53]$. In the skin it presents as single or multiple papules, usually resolving over several months. Disseminated JXG can occur, and usually presents as a solitary mass in deep tissues. Organs can be involved including CNS, and fatalities usually occur from CNS disease [10]. Ocular JXG occurs very rarely in very young children [52, 54]. Usually JXG follows a benign course, but disseminated forms are treated similarly to LCH.

Rosai Dorfman disease (RDD) (Fig. 11), also referred to "sinus histiocytosis with massive lymphadenopathy" in the lymph node, is a non-Langerhans cell histiocytosis which is common in children and young adults. Familial and sporadic forms occur. It is thought to be a non-neoplastic histiocytic disorder, but recent studies have identified NRAS, KRAS, MAP2K1 and ARAF clonal mutations [55]. RDD is characterized by a proliferation of cytokine activated histiocytes, and has been associated with IgG4 related disease, non-Hodgkin and Hodgkin lymphoma, leukemia and autoimmune disorders $[52,56]$. It is more commonly seen in males than females, and in patients of African descent. Painless enlarged cervical lymph nodes is the most common presentation; however, extra-nodal sites are involved in $43 \%$ of cases and occur in sites including the skin, soft tissue, bone, eye, retro-orbit, upper respiratory tract, liver, organ involvement, and CNS [46]. Head and neck masses are reported in $22 \%$ of cases. The diagnosis is typically made in a lymph node specimen showing massive enlargement and expansion of the sinuses by intra-sinusoidal histiocytes showing emperipolesis. The histiocytes show abundant cytoplasm with scattered polyclonal plasma cells. The histiocytes are immunoreactive for CD68, CD163, and S100, but are negative for CD1a and CD207. In pediatric head and neck cases, the most common complaints are nasal obstruction, neck swelling, facial swelling, and epistaxis; systemic symptoms can also be present. Most cases involve the otorhinolaryngologic sites with or without simultaneous non-otorhinolaryngologic site involvement. The nasal vault is the most common site (42\%) followed by the paranasal sinus (32\%). The most common non-rhinolaryngologic site is the orbit (57\%) [57]. Concurrent cervical lymphadenopathy is seen in $61 \%$ of patients with lymphadenopathy outside the head and neck observed in $37 \%$ of patients [57]. In extranodal sites, RDD may be more difficult to diagnose as emperipolesis is not always apparent, but a high level of suspicion and immunohistochemistry is helpful. The clinical course varies from self-limited with good outcome to organ involvement requiring treatment.

Histiocytic sarcoma $(H S)$ (Fig. 12a-c) is an extremely rare malignant non-Langerhans cell histiocytosis. The neoplastic cells resemble collections of histiocytes or macrophages but can be spindled with biologic and morphologic features of malignancy. The cells are generally large with abundant cytoplasm that can be foamy or vacuolated. Nuclear atypia 
Fig. 11 Rosai-DorfmanDisease; posterior mandible soft tissue from a 15-year-old. a Low-power view showing a histiocytic infiltrate in soft tissue. b Clusters of histiocytes with abundant cytoplasm and scattered lymphocytes. c Histiocytes showing emperipolesis. d CD68 positivity in the histiocytes. e CD163 positivity in the histiocytes. $f \mathrm{~S} 100$ positivity in the histocytes highlighting the emperipolesis
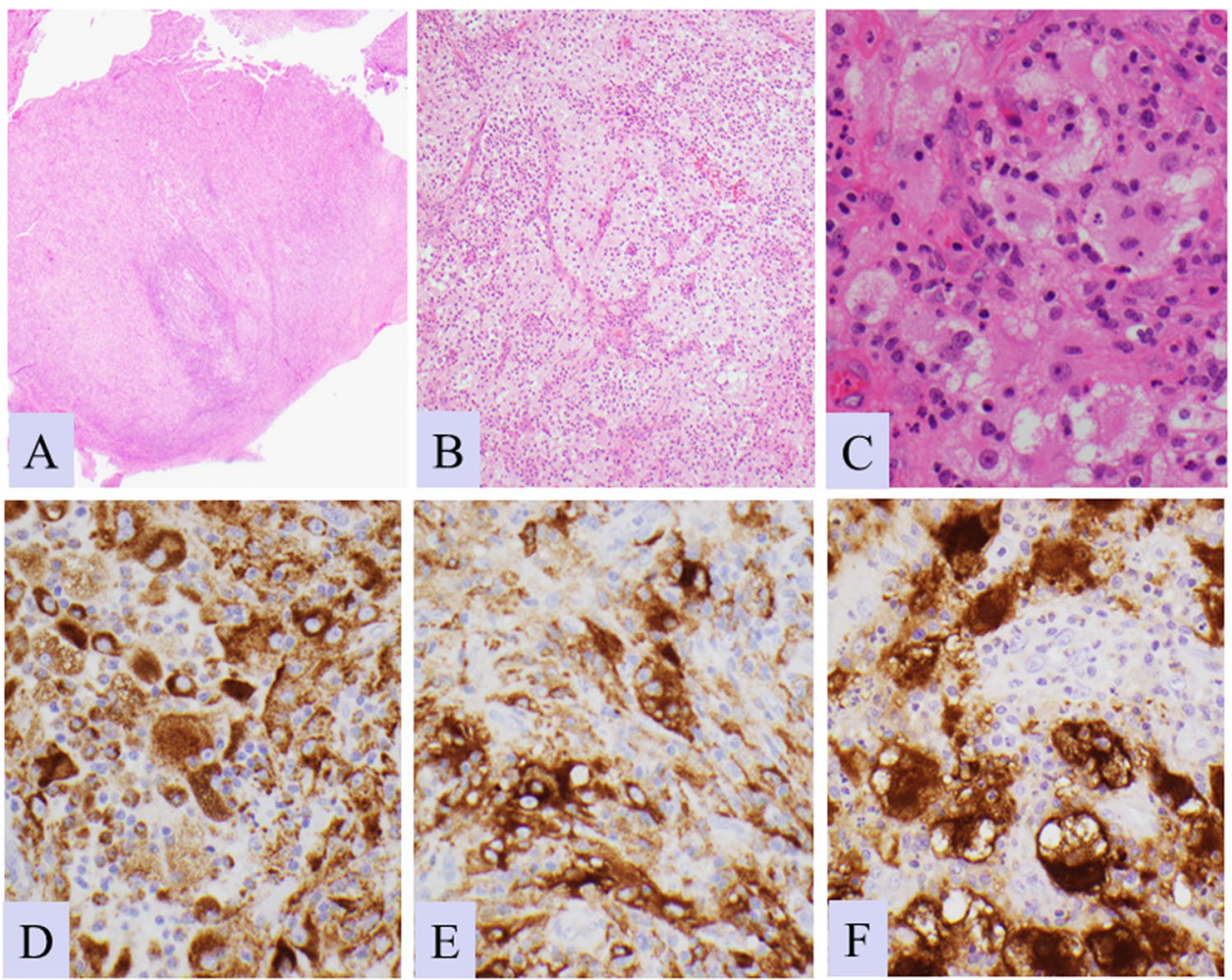

Fig. 12 a-c Histiocytic sarcoma; hard palate and left cervical lymph node (images) from a 5-year-old male. a The lymph node is effaced by an infiltrate of neoplastic histiocytes. b Although the histiocytes are somewhat bland there are mitoses. (C) CD163 positivity in the histiocytes. d-f Reticulohistiocytosis; subcutaneous neck mass from a 1-year-old male. $\mathbf{d}$ Low power if a histiocytic infiltrate in the soft tissue. e Medium power showing the characteristic pattern of histiocytes with surrounding lymphocytes. f Histiocytes showing glassy cytoplasm and surrounding lymphocytes
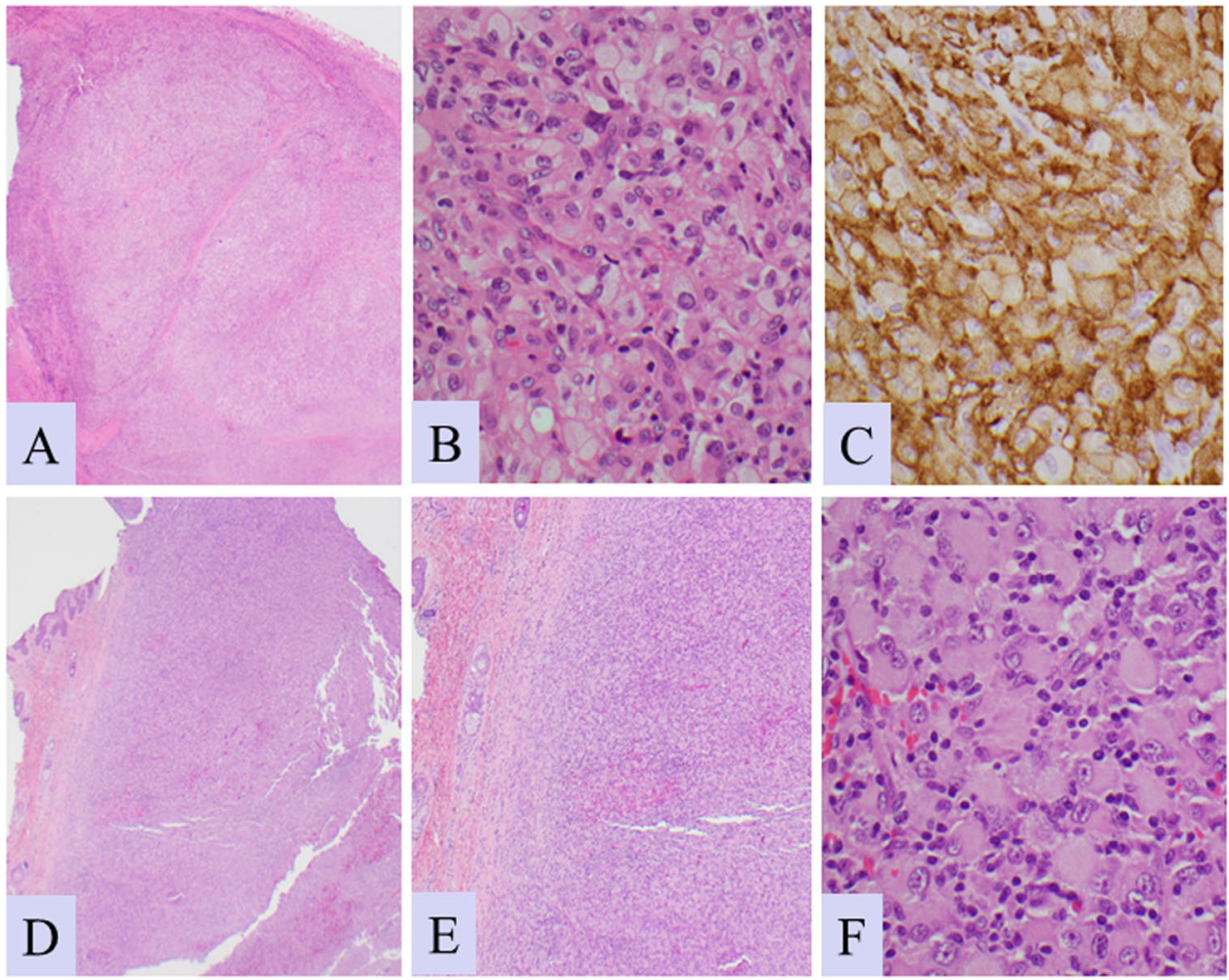

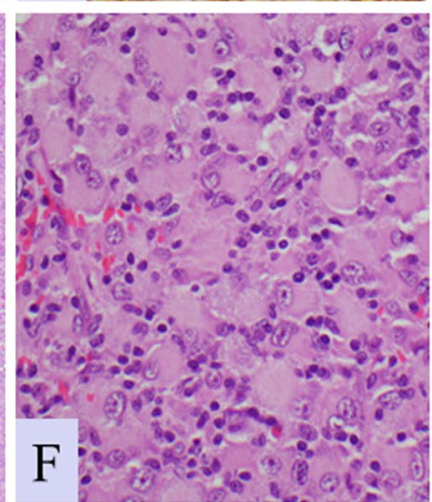

can vary from mild to severe. There are sporadic and secondary cases (usually following low grade B cell lymphomas) and both usually occur in adults. Malignant cells express one or more histiocyte markers such as CD68, CD163, lysozyme, and MAC387. S100 may be positive but is usually weak and patchy. CD1a, Langerin, and myeloperoxidase are negative. 
$I G H$ rearrangement may be clonal in both sporadic and secondary cases of HS and does not exclude the diagnosis. The true incidence of HS is unclear due to its rarity and inconsistent nomenclature. Its incidence in children is unknown, but there is a peak from age 0-29 years as well as a larger peak at 50-69 years [58, 59]. Lymph node is the most common site of disease, but many extranodal sites can be involved. Rare cases of HS in head and neck in children are reported in the literature including maxilla and mandible [60] and orbit [61]. In children, HS can follow lymphoblastic leukemia [62]. The diagnosis of HS is largely one of exclusion. One of the main differential diagnoses is myeloid sarcoma (MS), particularly extranodal involvement by acute monocytic/monoblastic leukemia (AML). Although bone marrow involvement is helpful in differentiating (AML/MS) from HS, bone marrow is not always involved at presentation for AML/MS. Next generation sequencing has found some differentiating mutations; BRAF V600E is the most common mutation in HS, but the mutation is not seen in AML or MS [63]. Response to treatment is poor, but localized disease can be excised, and patients can have more favorable outcomes.

Myeloid sarcoma $(M S)$ is an extramedullary presentation of acute myeloid leukemia and is extremely rare in children. MS can be the first presenting sign of AML and can precede bone marrow involvement or more commonly presents in conjunction with bone marrow involvement. In children, MS is seen most often with monocytic differentiation including acute monocytic or monoblastic leukemia, acute myelomonocytic leukemia, or sometime juvenile myelomonocytic leukemia. Histologically there is usually a mass lesion comprised of immature appearing myeloid cells with fine chromatin. The cells often stain as immature monocytic precursors with positivity for myeloperoxidase, CD68, CD163, lysozyme and sometimes CD34, CD117, CD123, or TdT. Immature markers are helpful in differentiating MS from HS. Abnormalities in FISH or cytogenetics typical of myeloid neoplasms can be found in many cases [64]. The most common site of MS involvement in children is skin, and the second most common site is orbit. Orbital involvement by MS presents as ptosis, lacrimal gland involvement, and a conjunctival mass similar to other orbital tumors [65]. Oral lesions can also rarely be seen in children [66]. Other sites in the head and neck include soft palate, nasopharynx, and face $[67,68]$. Prognosis is similar to AML and depends on the genetic findings.

$A L K$ positive histiocytosis $(A H)$ is an exceedingly rare histiocytic proliferation in early infancy which is generally systemic but can present locally. Localized lesions tend to be in older children; cavernous sinus lesions and nasal skin papules have been described [69-71]. Histomorphology shows large histiocytic cells with irregular folded nuclei, fine chromatin, and small nucleoli. Multinucleated Touton giant cells can rarely be seen, raising the differential of disseminated
JXG. Occasional cells show phagocytosis of lymphocytes suggestive of emperipolesis. Foamy cells can be seen but are not characteristic, raising the differential of Erdheim-Chester disease, a clonal histiocytosis seen predominately in adults. Immunohistochemical stains show diagnostic positivity for ALK in a cytoplasmic pattern. CD68, CD163, FXIIIa and fascin are also expressed. S100 is positive in $50 \%$ of cases, but $\mathrm{CD} 1 \mathrm{a}$, Langerin, and the $B R A F \mathrm{~V} 600 \mathrm{E}$ mutation are negative. The KIF5B-ALK fusion is the most frequent rearrangement in this entity, but other $A L K$ fusion partners have been described [69]. Prognosis may be good for these neoplasms, but data is limited.

Hemophagocytic lymphohistiocytosis $(H L H)$ is a systemic syndrome of pathologic activation of macrophages and associated T-cells which results in excess activation of the immune system and end organ damage $[72,73]$. There are familial (primary) cases, which are autosomal recessive, and acquired (secondary) types of HLH. To make the diagnosis of HLH, molecular diagnostic findings consistent with HLH must be present or five of eight clinical diagnostic criteria must be identified, which include fever, splenomegaly, cytopenias, hypertriglyceridemia and/or hypofibrinogenemia, hemophagocytosis in bone marrow, spleen or lymph nodes, low or absent NK-cell activity, hyperferritinemia, and high levels of sIL-2r [74]. Because only some of the criteria must be fulfilled, hemophagocytosis is not necessary for the diagnosis. Although the effector cells of HLH are non-neoplastic, the disorder is often fatal if not diagnosed or there is a delay in diagnosis. Familial HLH is usually seen in infancy or early childhood with a median survival of less than two months. Secondary HLH may develop in older children or adults as a result of infection or malignancy in patients that are not obviously immune compromised. EBV is often the trigger for secondary or familial HLH. Autopsy has documented that HLH is also associated with COVID-19 in a subset of patients [75]. In children with HLH, skin lesions are common [76], including generalized maculopapular rash, generalized erythroderma, edema and panniculitis, erythema, petechiae and purpura which are often non-specific by histology. Erythrophagocytosis sometimes seen in other tissues is rarely seen in skin. Cervical [77-79] and preauricular [79] lymphadenopathy, as well as necrotizing epiglottitis [80] have also been reported. Cerebral spinal fluid (CSF) is involved in many cases. Findings in lymph nodes include accumulation of macrophages and sometimes hemophagocytosis. Molecular diagnosis of HLH shows that the underlying gene defect often involves mutations of the perforin $(P R F)$ gene, which accounts for up to $50 \%$ of the familial cases in North America [74]. Other gene defects, including those involving UNC13D, STX11, $S T X B P 2, L Y S T, R A B 27 A, A P 3 B 1, S H 2 D 1 A$ and $X 1 A P$ are also associated with HLH; each gene defect is unique but all lead to impaired cytotoxic function of NK and T cells with 
predisposition to HLH [73]. Treatment consists of chemotherapy and immunosuppressive drugs targeting the overactive T cells and macrophages. Stem cell transplant is the only curative treatment for familial HLH.

Reticulohistiocytosis (RH) (Fig. 12d-f) is a dermal or subcutaneous histiocytic infiltration also referred to as "solitary epithelioid histiocytoma" or "reticulohistiocytoma". This entity occurs in both children and adults. Usually patients have solitary asymptomatic cutaneous or mucosal papules or nodules which never exceed $1 \mathrm{~cm}$ [81], but disseminated forms have been described. They occur in a wide variety of locations including the head and neck. Head and neck sites include neck, chin, earlobe, lower lip, nasal skin, buccal wall, and tongue. Histopathology shows large mononuclear epithelioid histocytes with abundant eosinophilic cytoplasm and admixed lymphocytes in varying amounts at the periphery or between the histiocytes. Acute inflammation is rare. Some multinucleated forms are present but Touton giant cells are not seen. Atypia and mitoses are rare. Cells are immunoreactive for CD68 and CD163, but factor XIIIa is generally negative. S100 is usually negative with exceptional cases showing low numbers of S100-positive cells. CD1a and Langerin are negative. Molecular studies have shown mutations in RAF1 and TSC2 in single case reports [82]. $B R A F$ V600E mutations have not been reported [83]. Treatment is local excision with low chance of recurrence.

In conclusion, this review describes selected non-neoplastic lymphoid disorders that can occur in children who present with head and neck lesions. In addition, several different types of lymphoma and histiocytic lesions common in the head and neck tissues of children are discussed. Changes in the newest (2017) version of the World Health Organization Classification of Tumours of Haematopoietic and Lymphoid Tumors includes the addition of some new entities described in this paper: large B-cell lymphoma with IRF4 rearrangement, pediatric-type follicular lymphoma and Burkitt-like lymphoma with 11q aberration. Recognition of these new entities allows for better classification of certain lesions which did not fit previously. For example, lymphoma that resembles Burkitt lymphoma, but lacks CMYC may represent Burkitt-like lymphoma with llq aberration. The differential diagnosis of lymphoma in the head and neck of children is broad but would include small round blue cell tumors and other sarcomas which are more common in children than adults. Entities like Ewing sarcoma and rhabdomyosarcoma can be mistaken for lymphoma on morphologic exam. Utilizing broad immunohistochemical panels starting with broad hematopoietic markers such as CD45, CD20, CD3 and CD43, followed by more specific panels such as CD5, CD10, CD23, BCL1, BCL2, BCL6 can typically separate out a lymphoma from a soft tissue tumor. Fine needle aspiration of head and neck lymph nodes or other masses can be used to adequately diagnosis a large number of these head and neck pediatric lymphoid and histiocytic lesions. Although the morphology of many lymphoid lesions is not specific by cytology; utilization of flow cytometry and immunohistochemistry to phenotype the lymphocytes as well as molecular testing (FISH, PCR and NGS) to detect genetic alterations can be used to diagnosis a large number of these lesions, Ultimately, lymphoid proliferations, both benign and neoplastic as well as histiocytic lesions in the head and neck of children is a highly interesting and everevolving group of heterogeneous medical diseases.

\section{Compliance with Ethical Standards}

Conflict of interest All author(s) declare that they have no conflict of interest as it relates to this research project.

Funding No external funding was obtained for this study.

Ethical approval All procedures performed in this retrospective data analysis involving human participants were in accordance with the ethical standards of the institutional review board, which did not require informed consent.

Disclaimer The views expressed in this [article, speech, presentation, etc.] are those of the author and do not reflect the official policy of the Department of Army/Navy/Air Force, Department of Defense, or U.S. Government. Compliance With Ethical Standards Conflict of interest: All author(s) declare that they have no conflict of interest as it relates to this research project. Funding: No external funding was obtained for this study. Ethical approval: All procedures performed in this retrospective data analysis involving human participants were in accordance with the ethical standards of the institutional review board, which did not require informed consent.

\section{References}

1. Weinstock MS, Patel NA, Smith LP. Pediatric cervical lymphadenopathy. Pediatr Rev. 2018;39:433-43.

2. Schowinsky J. Reactive and malignant diseases of hematopoietic and lymphoid tissues. In: Greer R, Marx R, Said SPL, editors. Pediatric Head and Neck Pathology. Cambridge: Cambrige University Press; 2017. p. 505-41.

3. O'Malley D. General reactive conditions in lymph node and spleen. In: O'Malley D, George T, Orazi A, Abbondanzo S, editors. Benign Reaction Conditional lymph node spleen, Atlas nontumor Pathological first Series fascicle. Washinton, DC: ARP; 2009.

4. Chisholm KM, Fleming MD. Histologic and laboratory characteristics of symptomatic and asymptomatic castleman disease in the pediatric population. Am J Clin Pathol. 2020;153:821-32.

5. Haap M, Wiefels J, Horger M, Hoyer A, Müssig K. Clinical, laboratory and imaging findings in Castleman's disease: the subtype decides. Blood Rev. 2018;32:225-34. https://doi.org/10.1016/j. blre.2017.11.005.

6. Sopfe J, Endres A, Campbell K, Hayes K, Trout AT, Liang X, et al. Castleman disease in pediatrics: Insights on presentation, treatment, and outcomes from a two-site retrospective cohort study. Pediatr Blood Cancer. 2019;66:1-9. 
7. Liu AY, Nabel CS, Finkelman BS, Ruth JR, Kurzrock R, van Rhee $F$, et al. Idiopathic multicentric Castleman's disease: a systematic literature review. Lancet Haematol. 2016;3:e163-75. https://doi. org/10.1016/S2352-3026(16)00006-5.

8. Luzuriaga K, Sullivan JL. Infectious mononucleosis. N Engl J Med. 2010;362:1993-2000.

9. Louissaint A, Ferry JA, Soupir CP, Hasserjian RP, Harris NL, Zukerberg LR. Infectious mononucleosis mimicking lymphoma: distinguishing morphological and immunophenotypic features. Mod Pathol. 2012;25:1149-59.

10. Swerdlow S, Campo E, Harris NL, Jaffe ES, Pileri S, Stein H, et al. WHO classification of Tumours of Haematopoietic and Lymphoid Tissues. revised 4th edition. Swerdlow S, Campo E, Harris NL, Jaffe ES, Pileri S, Stein H, et al., editors. Lyon Cedex 08: International Agency for Research on Cancer (IARC); 2017.

11. Albright JT, Pransky SM. Nontuberculous mycobacterial infections of the head and neck. Pediatr Clin N Am. 2003;50:503-14.

12. Lin MH, Kuo TT. Specificity of the histopathological triad for the diagnosis of toxoplasmic lymphadenitis: polymerase chain reaction study. Pathol Int. 2001;51:619-23.

13. Eapen M, Mathew CF, Aravindan KP. Evidence based criteria for the histopathological diagnosis of toxoplasmic lymphadenopathy. J Clin Pathol. 2005;58:1143-6.

14. Onciu M, Medeiros LJ. Kikuchi-Fujimoto. Lymphadenitis. 2003;10:204-11.

15. Wang T-J, Yang Y-H, Lin Y-T, Chiang B-L. Kikuchi-Fujimoto disease in children: clinical features and disease course. J Microbiol Immunol Infect. 2004;37:219-24.

16. Felgar RE, Furth EE, Wasik MA, Gluckman SJ, Salhany KE. Histiocytic necrotizing lymphadenitis (Kikuchi's disease): in situ end-labeling, immunohistochemical, and serologic evidence supporting cytotoxic lymphocyte-mediated apoptotic cell death. Mod Pathol. 1997;10:231-41.

17. Chamulak GA, Brynes RK, Nathwani BN. Kikuchi-Fujimoto disease mimicking malignant lymphoma. Am J Surg Pathol. 1990;14:514-23.

18. Sandlund JT, Martin MG. Non-Hodgkin lymphoma across the pediatric and adolescent and young adult age spectrum. Hematology. 2016;2016:589-97.

19. Sandlund JT. Non-Hodgkin Lymphoma in Children. Curr Hematol Malig Rep. 2015;10:237-43.

20. Etemad-Moghadam S, Tirgary F, Keshavarz S, Alaeddini M. Head and neck non-Hodgkin's lymphoma: A 20-year demographic study of 381 cases. Int J Oral Maxillofac Surg. 2010;39:869-72. https://doi.org/10.1016/j.ijom.2010.03.029.

21. Tadbir AA, Mehrabani D, Heydari ST. M 1538. 2007;2007:2002-5.

22. Keegan THM, Glaser SL, Clarke CA, Gulley ML, Craig FE, DiGiuseppe JA, et al. Epstein-Barr virus as a marker of survival after Hodgkin's lymphoma: a population-based study. J Clin Oncol. 2005;23:7604-13.

23. Claviez A, Tiemann M, Lüders H, Krams M, Parwaresch R, Schellong $\mathrm{G}$, et al. Impact of latent Epstein-Barr virus infection on outcome in children and adolescents with Hodgkin's lymphoma. J Clin Oncol. 2005;23:4048-56.

24. Urquhart A, Berg R. Hodgkin 's and Non-Hodgkin 's Lymphoma of the Head and Neck.

25. Shamloo N, Ghannadan A, Jafari M, Ahmadi S, Mortazavi H, Baharvand M. Head and neck lymphoma in an Iranian population. Iran J Otorhinolaryngol. 2017;29:261-7.

26. del Quiñones-Avila MP, Gonzalez-Longoria AA, Admirand $\mathrm{JH}$, Medeiros LJ. Hodgkin lymphoma involving Waldeyer ring: a clinicopathologic study of 22 cases. Am J Clin Pathol. 2005;123:651-6.
27. Dunphy CH, Saravia O, Varvares MA. Hodgkin's disease primarily involving Waldeyer's ring. Case report and review of the literature. Arch Pathol Lab Med. 1996;120:285-7.

28. Kapadia SB, Roman LN, Kingma DW, Jaffe ES, Frizzera G. Hodgkin's disease of Waldeyer's ring. Clinical and histoimmunophenotypic findings and association with Epstein-Barr virus in 16 cases. Am J Surg Pathol. 1995;19:1431-9.

29. Cionini L, Bastiani P, Biti GP, Mungai V, Ponticelli P, Di Lollo S. Waldeyer's ring (WR) involvement in Hodgkin's disease. Radiother Oncol. 1985;3:299-302.

30. Burkitt DP. The discovery of Burkitt's lymphoma. Cancer. 1983;51:1777-86.

31. Rohde M, Bonn BR, Zimmermann M, Lange J, Möricke A, Klapper W, et al. Relevance of ID3-TCF3-CCND3 pathway mutations in pediatric aggressive B-cell lymphoma treated according to the non-Hodgkin lymphoma Berlin-Frankfurt-münster protocols. Haematologica. 2017;102:1091-8.

32. Havelange V, Pepermans X, Ameye G, Théate I, Callet-Bauchu $\mathrm{E}, \mathrm{Barin} \mathrm{C}$, et al. Genetic differences between paediatric and adult Burkitt lymphomas. Br J Haematol. 2016;173:137-44.

33. Gonzalez-Farre B, Ramis-Zaldivar JE, Salmeron-Villalobos J, Balagué O, Celis V, Verdu-Amoros J, et al. Burkitt-like lymphoma with $11 \mathrm{q}$ aberration: a germinal center-derived lymphoma genetically unrelated to Burkitt lymphoma. Haematologica. 2019;104:1822-9.

34. Thunberg U, Amini RM, Linderoth J, Roos G, Enblad G, Berglund M. BCL2 expression in de novo diffuse large B-cell lymphoma partly reflects normal differences in age distribution. Br J Haematol. 2009;146:683-4.

35. Szczepanowski M, Lange J, Kohler CW, Masque-Soler N, Zimmermann M, Aukema SM, et al. Cell-of-origin classification by gene expression and MYC-rearrangements in diffuse large B-cell lymphoma of children and adolescents. Br J Haematol. 2017;179:116-9.

36. Msimang M, Ramdial P, Kuppusamy J, Nargan K, Sheik GM. AIDS-associated pdiatric high grade B-cell lymphoma with MYC and BCL2 translocations. J AIDS Clin Res. 2017;8:742.

37. Sukswai N, Lyapichev K, Khoury JD, Medeiros LJ. Diffuse large B-cell lymphoma variants: an update. Pathology. 2020;52:53-67.

38. Ramis-Zaldivar JE, Gonzalez-Farré B, Balagué O, Celis V, Nadeu F, Salmerón-Villalobos J, et al. Distinct molecular profile of IRF4rearranged large B-cell lymphoma. Blood. 2020;135:274-86.

39. Nguyen KA, Su C, Bai HX, Zhang Z, Xiao R, Karakousis G, et al. Disease site as a determinant of survival outcome in patients with systemic anaplastic lymphoma kinase positive anaplastic large cell lymphoma with extranodal involvement: an analysis of 1306 cases from the US National Cancer Database. Br J Haematol. 2018;181:196-204.

40. Jaglowski SM, Linden E, Termuhlen AM, Flynn JM. Lymphoma in adolescents and young adults. Semin Oncol. 2009;36:381-418. https://doi.org/10.1053/j.seminoncol.2009.07.009.

41. Agostinelli C, Akarca AU, Ramsay A, Rizvi H, Rodriguez-Justo M, Pomplun S, et al. Novel markers in pediatric-type follicular lymphoma. Virchows Arch. 2019;475:771-9.

42. Rizzo KA, Streubel B, Pittaluga S, Chott A, Xi L, Raffeld M, et al. Marginal zone lymphomas in children and the young adult population: characterization of genetic aberrations by FISH and RT-PCR. Mod Pathol. 2010;23:866-73.

43. The Writing Group of the Histiocyte Society. Histiocytosis syndromes in children. Lancet. 1987;1:208-9.

44. Golpanian S, Tashiro J, Gerth DJ, Thaller SR. Pediatric histiocytoses in the United States: incidence and outcomes. J Surg Res. 2014;190:221-9. https://doi.org/10.1016/j.jss.2014.03.063.

45. Robinson LD, Smith RJ, Rightmire J, Torpy JM, Fernbach DJ. Head and neck malignancies in children: an age-incidence study. Laryngoscope. 1988;98:11-3. 
46. Emile J-F, Abla O, Fraitag S, Horne A, Haroche J, Donadieu J, et al. Review article revised classification of histiocytoses and neoplasms of the macrophage-dendritic cell lineages. Blood. 2016;127:2672-82.

47. Kaatsch P. Epidemiology of childhood cancer. Cancer Treat Rev. 2010;36:277-85. https://doi.org/10.1016/j.ctrv.2010.02.003.

48. Grana N. Langerhans cell histiocytosis. Cancer Control. 2014;21:328-34.

49. Leung AKC, Lam JM, Leong KF. Childhood Langerhans cell histiocytosis: a disease with many faces. World J Pediatr. 2019;15:536-45. https://doi.org/10.1007/s12519-019-00304-9.

50. Anonsen CK, Donaldson SS. Langerhans' cell histiocytosis of the head and neck. Laryngoscope. 1987;97:537-42.

51. Buchmann L, Emami A, Wei JL. Primary head and neck Langerhans cell histiocytosis in children. Otolaryngol Head Neck Surg. 2006;135:312-7.

52. Haroche J, Abla O. Uncommon histiocytic disorders: Rosai-Dorfman, juvenile xanthogranuloma, and Erdheim-Chester disease. Hematology. 2015;2015:571-8.

53. Flaitz C, Allen C, Neville B, Hicks J. Juvenile xanthogranuloma of the oral cavity in children: a clinicopathologic study. Oral Surg Oral Med Oral Pathol Oral Radiol Endod. 2002;94:345-52.

54. Murphy JT, Soeken T, Megison S, Perez E. Juvenile xanthogranuloma: diverse presentations of noncutaneous disease. J Pediatr Hematol Oncol. 2014;36:641-5.

55. Goyal G, Ravindran A, Young JR, Shah MV, Bennani NN, Patnaik $\mathrm{MM}$, et al. Clinicopathological features, treatment approaches, and outcomes in Rosai-Dorfman disease. Haematologica. 2020;105:348-57.

56. Abla O, Jacobsen E, Picarsic J, Krenova Z, Jaffe R, Emile JF, et al. Consensus recommendations for the diagnosis and clinical management of Rosai-Dorfman-Destombes disease. Blood. 2018;131:2877-90.

57. Alwani MM, Elghouche AN, Schueth EA, Campiti VJ, Matt BH, Yekinni AO. Manifestations of pediatric extranodal Rosai Dorfman disease in the head and neck. Int J Pediatr Otorhinolaryngol. 2020;131:109851. https://doi.org/10.1016/j.ijporl.2019.109851.

58. Takahashi E, Nakamura S. Histiocytic sarcoma: an updated literature review based on the 2008 WHO classification. J Clin Exp Hematop. 2013;53:1-8.

59. Skala SL, Lucas DR, Dewar R. Histiocytic sarcoma: review, discussion of transformation from B-cell lymphoma, and differential diagnosis. Arch Pathol Lab Med. 2018;142:1322-9.

60. Bhalla V, Khan N, Jones M, Kumar A, Latifaj B, Colmenero I, et al. A rare case of paediatric histiocytic sarcoma of the maxilla and mandible. Dentomaxillofacial Radiol. 2016;45:20150393.

61. Aakalu VK, Patel RM, Lim J, Setabutr P. Orbital histiocytic sarcoma in a 2-year-old child. Ophthal Plast Reconstr Surg. 2014;30:e143-5.

62. Castro ECC, Blazquez C, Boyd J, Correa H, De Chadarevian JP, Felgar RE, et al. Clinicopathologic features of histiocytic lesions following ALL, with a review of the literature. Pediatr Dev Pathol. 2010;13:225-37.

63. Liu Q, Tomaszewicz K, Hutchinson L, Hornick JL, Woda B, Yu H. Somatic mutations in histiocytic sarcoma identified by next generation sequencing. Virchows Arch. 2016;469:233-41. https ://doi.org/10.1007/s00428-016-1965-2.

64. Klco JM, Welch JS, Nguyen TT, Hurley MY, Kreisel FH, Hassan A, et al. State of the art in myeloid sarcoma. Int J Lab Hematol. 2011;33:555-65.

65. Samborska M, Derwich K, Skalska-Sadowska J, Kurzawa P, Wachowiak J. Myeloid sarcoma in children: diagnostic and therapeutic difficulties. Wspolczesna Onkol. 2016;20:444-8.

66. Gaal A, Chisholm KM, Egbert M. How rare is an oral presentation of myeloid sarcoma in the infant? J Oral Maxillofac Surg. 2018;76:561-8. https://doi.org/10.1016/j.joms.2017.08.034.
67. Cuthbertson DW, Punia JN, Owczarzak VL. Myeloid sarcomas of the head and neck in pediatric patients with myeloid leukemia. Ear Nose Throat J. 2016;95:405-7.

68. Roby BB, Drehner D, Sidman JD. Granulocytic sarcoma of pediatric head and neck: an institutional experience. Int J Pediatr Otorhinolaryngol. 2013;77:1364-6. https://doi.org/10.1016/j.ijpor 1.2013.06.008.

69. Chang KTE, Tay AZE, Kuick CH, Chen H, Algar E, Taubenheim $\mathrm{N}$, et al. ALK-positive histiocytosis: an expanded clinicopathologic spectrum and frequent presence of KIF5B-ALK fusion. Mod Pathol. 2019;32:598-608.

70. Lucas CHG, Gilani A, Solomon DA, Liang X, Maher OM, Chamyan G, et al. ALK-positive histiocytosis with KIF5B-ALK fusion in the central nervous system. Acta Neuropathol. 2019;138:335-7. https://doi.org/10.1007/s00401-019-02027-7.

71. Chan JKC, Lamant L, Algar E, Delsol G, Tsang WYW, Lee KC, et al. ALK+ histiocytosis: a novel type of systemic histiocytic proliferative disorder of early infancy. Blood. 2008;112:2965-8.

72. Allen CE, Kelly KM, Bollard CM. Pediatric lymphomas and histiocytic disorders of childhood. Pediatr Clin N Am. 2015;62:139-65.

73. Usmani GN, Woda BA, Newburger PE. Advances in understanding the pathogenesis of HLH. Br J Haematol. 2013;161:609-22.

74. Henter J-I, Horne A, Aricó M, Egeler RM, Filipovich AH, Imashuku S, et al. HLH-2004: diagnostic and therapeutic guidelines for hemophagocytic lymphohistiocytosis. Pediatr Blood Cancer. 2007;48:124-31.

75. Prilutskiy A, Kritselis M, Shevtsov A, Yambayev I, Vadlamudi C, Zhao Q, et al. SARS-CoV-2 infection-associated hemophagocytic lymphohistiocytosis. Am J Clin Pathol. 2020;154:466-74.

76. Morrell DS, Pepping MA, Scott JP, Esterly NB, Drolet BA. Cutaneous manifestations of hemophagocytic lymphohistiocytosis. Arch Dermatol. 2002;138:1208-12.

77. Lindemann TL, Greene JS. Persistent cervical lymphadenopathy in an adolescent with Epstein-Barr induced hemophagocytic syndrome: manifestations of a rare but often fatal disease. Int $\mathbf{J}$ Pediatr Otorhinolaryngol. 2005;69:1011-4.

78. Lang S, Kansy B. Cervical lymph node diseases in children. GMS Curr Top Otorhinolaryngol Head Neck Surg. 2014;13:08.

79. Ghanaiee RM, Shiari R, Karimi A, Armin S, Fahimzad A, Shiva F, et al. A case series report of Iranian children: hemophagocytic lymphohistiocytosis syndrome. Arch Pediatr Infect Dis. 2013;1:31-5.

80. Kong MS, Engel SH, Zalzal GH, Preciado D. Necrotizing epiglottitis and hemophagocytic lymphohistiocytosis. Int J Pediatr Otorhinolaryngol. 2009;73:119-25.

81. Miettinen M, Fetsch JF. Reticulohistiocytoma (Solitary Epithelioid Histiocytoma). Am J Surg Pathol. 2006;30:521-8.

82. Bahrani E, Fernandez-Pol S, Wang JY, Aasi SZ, Brown RA, Novoa RA. Reticulohistiocytoma (solitary epithelioid histiocytoma) with mutations in RAF1 and TSC2. J Cutan Pathol. 2020. https://doi.org/10.1111/cup.13727.

83. Hoyt BS, Yan S, Linos KD, Momtahen S, Sriharan A, Tran TAN, et al. BRAF V600E mutations are not an oncogenic driver of solitary xanthogranuloma and reticulohistiocytoma: testing may be useful in screening for Erdheim-Chester disease. Exp Mol Pathol. 2019;111:104320. https://doi.org/10.1016/j.yexmp.2019.104320.

Publisher's Note Springer Nature remains neutral with regard to jurisdictional claims in published maps and institutional affiliations. 